Lee, Young-Gill

Kim, Cheolho

Park, Jeong-Ho

Kim, Hyeongjun

Lee, Insu

Jin, Bongyong

http://dx.doi.org/10.21278/brod70204

ISSN 0007-215X

eISSN 1845-5859

\title{
NUMERICAL SIMULATIONS OF ADDED RESISTANCE IN REGULAR HEAD WAVES ON A CONTAINER SHIP
}

UDC 629.5.015.2:629.5.017.2:629.544

Original scientific paper

\begin{abstract}
Summary
Although shipping was not included in the final text of the Paris Agreement in 2015, IMO (International Maritime Organization) adopted the EEDI (Energy Efficiency Design Index) and the EEOI (Energy Efficiency Operational Indicator) to control climate change and also to reduce gas emission from ships. Accurate prediction of added resistance in waves is essential to evaluate the minimum fuel consumption of a ship in a real sea state. In this paper, the added resistance and motions of a KCS (KRISO Container Ship) with rudder were calculated using a commercial CFD program, STAR-CCM+. Wave forcing was used to generate the waves in the numerical domain, in which no extra wave generation and damping zones were produced. DFBI (Dynamic Fluid Body Interaction) was used for the motions of the KCS with rudder. In this study, five (5) regular head waves from a short wavelength to a long wavelength based on the LPP were considered. Finally, added resistance and the heave and pitch motions of the simulation were compared with experimental data. Simulation and experimental data were in qualitatively and quantitatively good agreement.
\end{abstract}

Key words: $\quad$ Added resistance; Ship motion; Regular head wave, Computational fluid dynamics; STAR-CCM+

\section{Introduction}

Although shipping was not included in the final text of the Paris Agreement adopted in 2015, the IMO (International Maritime Organization) has been making efforts to cope with climate change by regulating the amount of air pollutants and greenhouse gas emissions from ships, and introduced EEOI (Energy Efficiency Operational Indicator) for ships in operation and EEDI (Energy Efficiency Design Index) for new ships. In order to meet these requirements, it is essential to estimate the resistance and propulsion performance of a ship in waves to predict minimum energy consumption rate through experiments or numerical simulations. However, most previous research on ship resistance has dealt with resistance in the calm condition. Nonetheless, ships sailing in real sea conditions experience more 
resistance than in the calm condition due to winds and waves. The resistance induced winds and waves are called air resistance and added resistance, respectively. In the case of high speed craft in waves, more than $30 \%$ of total resistance is taken up by added resistance ([1], [2]) and ship speed can be reduced by over $10 \%$ because of waves [3].

Research on added resistance of ships in waves has been carried out for decades. Research in early 1970 was performed based on experiments on the Series 60 ([4], [5]) and S175 container ship model ([6], [7]), etc. Later, Journee [8] systematically carried out added resistance experiments for four Wigley hull form and Kuroda, et al. [9] have recently studied added resistance based on experiments while changing the bow shape of a container ship. Also, Park, et al. [10] proposed a study on uncertainty for reliability evaluation of added resistance experimental values through repeated experiments in various cases [11].

Both the experimental studies and theoretical and numerical approaches have been performed. Most initial stage research based on potential theory can be classified into a momentum conservation or pressure integration methods based on analysis method. The momentum conservation method was proposed by Mauro [12] and it has been widely used because added resistance can be obtained with a relatively simple calculation and without computing pressures on ship surfaces. Although equations of the pressure integration method are complicated, it is useful for physical analysis [13]. In the past, strip theory was mostly used to calculate motion for added resistance analysis. However, thanks to improved computational performance, added resistance analysis using a 3D Green function method and a Rankine panel method in frequency domain, and a higher-order Rankine panel method are being studied [14]. Seo, et al. [15] dealt with changing patterns of added resistance due to changes in hull forms of KCS and KVLCC2 above water lines using a nonlinear motion analysis method with a time-domain Rankine panel method. Oh \& Yang [16] developed added resistance computation module by using a modified radiated energy method and short wave correction method of NMRI so that the module can be used in the initial design or embedded module for navigation support systems. Jeong, et al. [17] performed sensitivity analysis of added resistance and weather factors in the representative sea state for initial hull form design stage and also analyzed added resistance for KVLCC2 and Supramax in waves by using a momentum conservation method.

Although methods based on potential theory have been useful in the realistic design stage, practical results cannot be obtained when the heights of incoming waves are high or ship motions become excessive [18]. In order to overcome this limitation, research on added resistance analysis using CFD (Computational Fluid Dynamics) taking viscosity into account due to recent improvements in hardware. Orihara and Miyata [19] studied on numerical simulation with WISDAM-X which developed by themselves using an overlapping grid system for analysis of added resistance and motions of an SR-108 container ship in regular head waves. Hu and Kashiwagi [20] used a Constrained Interpolation Profile (CIP) method and a rectangular grid system for analysis of added resistance. Visonneau, et al. [21] performed added resistance analysis in regular head waves by using ISIS-CFD, in which unstructured mesh and analytical weighting mesh deformation are adopted. Park, et al. [22] analyzed motions of a DTMB 5415 hull form in regular head waves by using WAVIS-6DoF with a fixed grid system and compared the results with experimental results. Yang, et al. [23] used a THINC (Tangent Hyperbola for Interface Capturing) method and a rectangular grid system based on a numerical method to analyze motions and added resistance of a Wigley III hull form and S175 container ship. Jeong \& Lee [18] exploited a modified Marker-density method and a rectangular grid system for a vortex induced vibration (VIV) analysis for a circular cylinder also performed motions and added resistance analysis on Wigley III and KCS hull forms and compared the simulation results with public experimental results. Tezdogan et al. [24] performed a fully nonlinear unsteady RANS simulation to predict the 
ship motions and added resistance of a full scale KRISO Container Ship model and estimated the increase in effective power and fuel consumption due to its operation in waves. Oh, et al. [14] carried out added resistance model tests in waves with both the original and Ax-bow hull form of an AFRAMAX-Class tanker, performed numerical simulations by a using Rankine panel method based 3D time domain motion analysis program(WISH) and a commercial CFD program(STAR-CCM+). The simulation results were compared with the model test results. Seo \& Park [11] used open source library OpenFOAM to compute added resistance and motion performance of a KCS hull form in regular head waves, and compared the results with public experimental results. Kim \& Lee [25] also exploited OpenFOAM to analyze resistance performance of a KCS hull form depending on trim conditions in regular waves. In spite of the research being performed, high accuracy of numerical simulation remains a challenge.

In previous research, a wave generation zone to create waves and damping zones to prevent and cancel out reflection of waves are set when generating waves. A domain corresponding to 1-2 times the wave domain, except for the computational domain, has to be generally generated. Furthermore, when the body-fitted grid system is exploited for motion analysis in waves, the re-fining or moving of the grid system according to the moving body is required as well. The necessary algorithm is complicated and requires significant computational time [18].

In this research, added resistance in regular head waves on KCS was studied. The commercial CFD software STAR-CCM+ V11.06 was used for numerical analysis while not setting wave generating and damping zones, and a method that does not require refining and moving the grid system was adopted. The experiment was performed in a FORCE Technology organization and the simulation results were compared with the public results in a 2015 Tokyo workshop (Case 2.10) [26].

\section{Numerical simulation methods}

The mass conservation equation and the momentum conservation equations including turbulence model were calculated in the incompressible based unsteady state. For the coupling of velocity and pressure, a SIMPLE [27] method was used, and Standard K-Epsilon Low-Re model and wall function were selected as the turbulence model. In order to increase the convergence performance of linear algebraic equation AMG (Algebraic Multi-Grid) method [28] was used. And using Gauss-Seidel method the simultaneous linear equation solved. Fifth-order Stokes wave theory was applied to express waves and the wave forcing method, which is a built-in method of STAR-CCM+, was used to minimize wave reflections at the boundary, which should be non-reflecting. The governing equations and numerical schemes are represented in Table 1.

The mass conservation equation and the momentum equations, which are governing equations for numerical simulation, are expressed as shown in equation (1) and (2), respectively.

$$
\begin{aligned}
& \frac{d}{d t} \int_{V} \rho d V+\int_{S} \rho \vec{v} \times \vec{n} d S=0 \\
& \frac{d}{d t} \int_{V} \rho u_{i} d V+\int_{S} \rho u_{i} \vec{v} \times \vec{n} d S=\int_{S}\left(\tau_{\vec{i} j} \overrightarrow{u_{J}}-p \overrightarrow{u_{i}}\right) \times \vec{n} d S+\int_{V} \rho g \overrightarrow{u_{u}} d V+\int_{V}
\end{aligned}
$$

$V$ is a finite volume limited by a closed surface $S, \vec{v}$ is the fluid velocity vector including velocity of $u_{i}$ and the unit vector which is vertical to $S$ and towards outer direction is $\vec{n}$. $t$ is time, $\mathrm{p}$ is pressure, $\rho$ is fluid density, $\tau_{i j}$ is viscous stress tensor and $\overrightarrow{r_{j}}$ is the unit vector in the 
$x_{j}$-direction. $\mathrm{g}$ is the gravitational acceleration and $q_{i}$ is the momentum source term. In this study, 2 numerical options which control the free surface wave around boundaries. One is wave damping [29] and the other is wave forcing [30] boundary option. A combination of linear and second-order damping, and one or a combination of both can be used for wave damping. The following equation (3) is used as the source term in equation (2) expressed in tensor form.

$$
\begin{aligned}
& q_{z}^{d}=\rho\left(f_{1}+f_{2}|w|\right) \frac{e^{k}-1}{e^{1}-1} w \\
& \kappa=\left(\frac{x-x_{s d}}{x_{\text {erd }}-x_{\text {sed }}}\right)^{n}
\end{aligned}
$$

Where $\mathrm{z}$ is the vertical direction with regard to the free surface, $\mathrm{w}$ is the $\mathrm{z}$-direction velocity component, $x_{\text {sd }}$ is the starting point of wave damping propagating in the $\mathrm{x}$-direction and $x_{\text {ed }}$ is the location where wave damping ends. $f_{1}$ and $f_{2}$ are the linear and the secondorder damping coefficients, respectively. Factor $f_{1}$ and $f_{2}, \mathrm{n}=2$. are can be changed for control the strength of damping. As we can see in equation defining $\kappa=\left(\frac{x-x_{g d}}{x_{g d}-x_{g d}}\right)^{n}$, the value of $\kappa=\left(\frac{x-x_{s d}}{x_{e d}-x_{g d}}\right)^{n}$ can be changed on range of the damping zone applied in numerical domain.

Wave forcing is a technique blending the CFD solution and the undisturbed wave solution. This boundary option is the same concept as EOM (Euler Overlay Method) which is applied in research by Kim et al. [30]. It is used to prevent the scattered waves at the body from coming into the CFD domain after being reflected at the boundaries. In EOM method [30], additional source term is added to each conservation equation. The new source term is given by following.

$$
S_{\phi}^{*}=S_{\phi}-\mu \rho\left(\phi-\phi_{E}\right) \text { in D }
$$

$\phi_{E}$ is the reference value from theoretical wave sloution. Navier-Stokes equations discretized at a certain distance are applied by other theoretical solutions, the calculation efficiency can be increased by reducing the size of the solution domain. Like EOM method, wave forcing can remove the problem related to wave reflection at the boundaries due to the damping characteristics of gradual constraint. Likewise wave damping, equation (4) is used as the source term in equation (2) expressed in tensor form. As equation (4) is the newly defined source term, it reduces the difference between the CFD solution and the undisturbed wave solution. $u_{i, r e f}$ is a reference velocity component and $u_{i}$ is a velocity component.

$$
\gamma=\gamma_{r e f} \cos ^{2}\left(\frac{\pi}{2}+\frac{\pi}{2} \frac{x-x_{g d}}{x_{e d}-x_{g d}}\right)
$$

Equation (5) identifies the forcing coefficient $\gamma$, which has same purpose of $\mu$ in equation (4). The wave forcing technique enables gradual application of the constraint described above to dampen the difference between forced and recent solutions at each computational time by applying the characteristics of the spatial distribution of the $\gamma$ value. In equation (5), $\gamma_{r e f}$ refers to the maximum value of $\gamma$. The forcing coefficient $\gamma$ represents the strength of forcing. It has a cosine form as shown in equation (5). The point where $\gamma$ has its maximum value spatially refers to the boundary surface at which it becomes the minimum at which forcing ends. If the value of $\gamma$ is at a maximum, which means the boundary, the 
theoretical solution of the transport equation will become the same as the calculated solution of the transport equation at each computational time.

Table 1 Governing equations and numerical scheme

\begin{tabular}{|c|c|}
\hline Governing equations & Reynolds-averaged Navier-Stokes(RANS) equations \\
\hline Free surface and wave & Volume of fluid method (VOF), Stokes' 5th-order wave \\
\hline Body motion & Dynamic fluid body interaction (DFBI), Heave and pitch free \\
\hline Turbulent model & Standard K-Epsilon Low-Re, All y+ Wall Treatment \\
\hline Mesh & Trimmed mesh \& prism layer with wall function \\
\hline
\end{tabular}

\section{Principal particulars of KCS and numerical simulation conditions}

The experiment was performed in FORCE Technology and a KCS (KRISO Container Ship) is used in both the numerical simulation and experiment. The scale of the model ship used in the simulation is $1 / 37.89$, the main particulars and the geometry are represented in Table 2. and Fig. 1 Geometric model of KCS with rudder and section lines of the fore-body, respectively. The speed of the model ship is $2.006 \mathrm{~m} / \mathrm{s}$, which is the design speed.

Assuming infinite water depth, simulation conditions were defined as shown in Table 3. Trim and sinkage were free and other motions were fixed. The waves were generated using the Stokes' 5th-order wave.

In order to generate waves which have a significant effect on the accuracy of analysis, the girds were generated, varying with the height of each incoming wave. In this research, 10 to 20 grids were generated in the incoming waves along the vertical direction and the ratio of the horizontal and vertical grid size $\Delta \mathrm{x} / \Delta \mathrm{z}$ was constrained at 8 . The number of grids used and the size of vertical direction grid sizes used for wave generation are shown in

Table 5 for each wave condition. The base size of grids used for all computations is $0.15 \mathrm{~m}$. In order to increase the accuracy of wave generation, a wave forcing technique was used [31].

The numerical computation domain used in this research for the resistance in calm water condition and the added resistance in waves is illustrated in Fig. 2. The origin of the coordinate system is $(0,0,0)$ which is at AP (After Perpendicular), Center line $(Y=0)$ and Base line $(Z=0)$, and the upward vertical direction was defined as $+z$. Time step size which is used in resistance calculation in calm water is chosen as $0.02 \mathrm{~s}$ to restrict courant number under 1.0.

The boundary conditions on the simulation of the resistance calculation in the calm water condition and the added resistance calculations in waves are shown in Table 4 . The wall boundary condition was applied to the hull surface and rudder in order to meet the non-slip condition. In the case of the resistance analysis in the calm water condition, LPP/2 of wave damping was applied at the inlet, outlet and side boundaries as shown in Fig. 2 [31]. For the added resistance analysis in waves, the wave forcing length was applied as shown in Fig. 3. Fig. 4 shows the generated grid for the added resistance analysis in waves. Fig. 5 represents the $2.5 \mathrm{D}$ grids which were generated to verify if the generated wave without ship hull was accurate and reproducible. 
Young-Gill Lee, Cheolho Kim, Jeong-Ho Park

, Hyeongjun Kim, Insu Lee, Bongyong Jin
Numerical simulations of added resistance in regular head waves on a container ship

Table 2 Main particulars of KCS with rudder

\begin{tabular}{|c|c|c|}
\hline Main particulars & Full scale & Model scale \\
\hline Length between perpendiculars, LPP $(\mathrm{m})$ & 230 & 6.0702 \\
\hline Maximum beam of waterline $(\mathrm{m})$ & 32.2 & 0.8498 \\
\hline Draft $(\mathrm{m})$ & 10.8 & 0.2850 \\
\hline Displacement volume $\left(\mathrm{m}^{3}\right)$ & 52030 & 0.9571 \\
\hline Wetted surface area w/o rudder $\left(\mathrm{m}^{2}\right)$ & 9424 & 6.6177 \\
\hline Wetted surface area of rudder $\left(\mathrm{m}^{2}\right)$ & 115.0 & 0.0801 \\
\hline LCB $(\%$ LpP), fwd+ & -1.48 & -1.48 \\
\hline Vertical Center of Gravity $(\mathrm{from}$ keel $)(\mathrm{m})$ & & 0.378 \\
\hline Moment of Inertia $\left(\mathrm{K}_{\mathrm{xx}} / \mathrm{B}\right)$ & 0.40 & \\
\hline Moment of Inertia $\left(\mathrm{K}_{\mathrm{yy}} / \mathrm{LPP}_{\mathrm{pP}}, \mathrm{K}_{\mathrm{zz}} / \mathrm{LPP}\right)$ & 0.250 & 0.252 \\
\hline
\end{tabular}

Table 3 Wave conditions

\begin{tabular}{|c|c|c|c|c|}
\hline Case no. & $\lambda L_{P P}$ & Wave height $(\mathrm{m})$ & Wave length, $\lambda(\mathrm{m})$ & Wave steepness \\
\hline 0 & \multicolumn{4}{|c|}{ Calm water } \\
\hline 1 & 0.65 & 0.062 & 3.949 & 0.016 \\
\hline 2 & 0.85 & 0.078 & 5.164 & 0.015 \\
\hline 3 & 1.15 & 0.123 & 6.979 & 0.018 \\
\hline 4 & 1.37 & 0.149 & 8.321 & 0.018 \\
\hline 5 & 1.95 & 0.196 & 11.840 & 0.017 \\
\hline
\end{tabular}

Table 4 Boundary conditions

\begin{tabular}{|c|c|c|}
\hline \multirow{2}{*}{ Boundary } & \multicolumn{2}{|c|}{ Type } \\
\cline { 2 - 3 } & In calm & In wave \\
\hline Inlet & Velocity inlet & Velocity inlet \\
\hline Outlet & Pressure outlet & Pressure outlet \\
\hline Top & Velocity inlet & Velocity inlet \\
\hline Bottom & Velocity inlet & Velocity inlet \\
\hline Side & Symmetry plane & Symmetry plane \\
\hline Symmetry & Symmetry plane & Symmetry plane \\
\hline
\end{tabular}


Table 5 Number and size of mesh according to wave conditions

\begin{tabular}{|c|c|c|c|c|}
\hline Case no. & $\begin{array}{c}\text { Total mesh } \\
\text { number }\end{array}$ & $\begin{array}{c}\text { Relative Z size (\% of } \\
\text { base size) }\end{array}$ & $\begin{array}{c}\text { Mesh number in Z } \\
\text { per wave height }\end{array}$ & Time steps size (s) \\
\hline 1 & abt. $2.87 \mathrm{e}+06$ & 3.125 & abt. 13 & 0.0025 \\
\hline 2 & abt. $3.81 \mathrm{e}+06$ & 3.125 & abt. 16 & 0.0025 \\
\hline 3 & abt. $4.48 \mathrm{e}+06$ & 3.125 & abt. 26 & 0.00125 \\
\hline 4 & abt. $1.60 \mathrm{e}+06$ & 6.250 & abt. 15 & 0.0025 \\
\hline 5 & abt. $1.66 \mathrm{e}+06$ & 6.250 & abt. 20 & 0.0025 \\
\hline
\end{tabular}

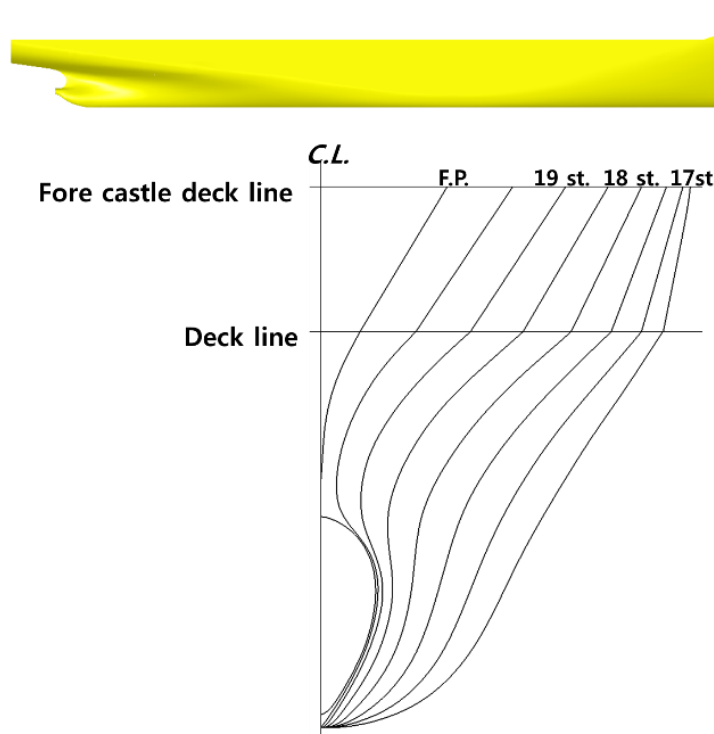

Fig. 1 Geometric model of KCS with rudder and section lines of the fore-body

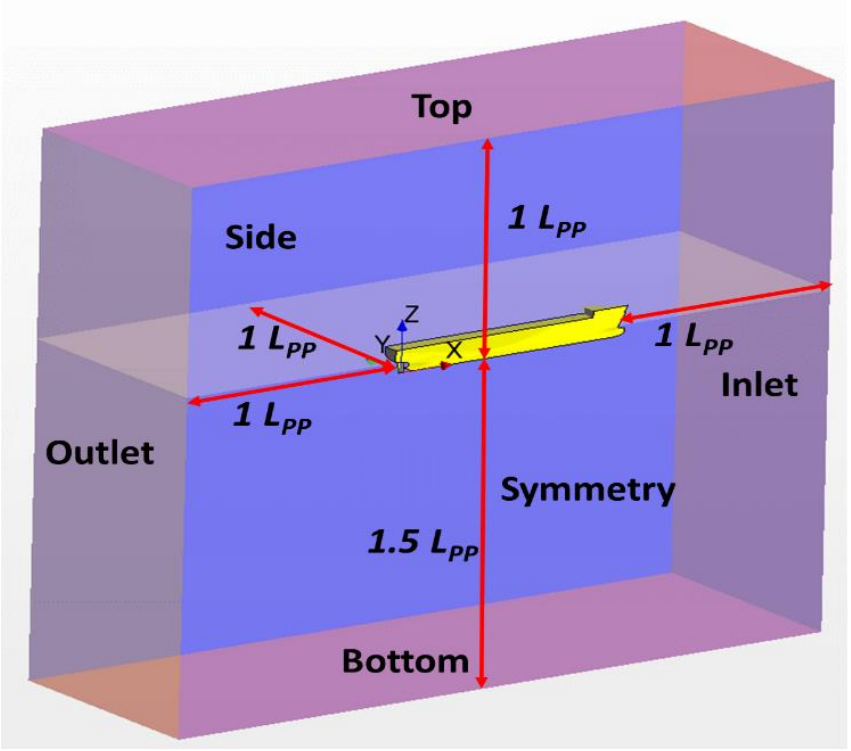

Fig. 2 Numerical domain in calm and wave conditions 


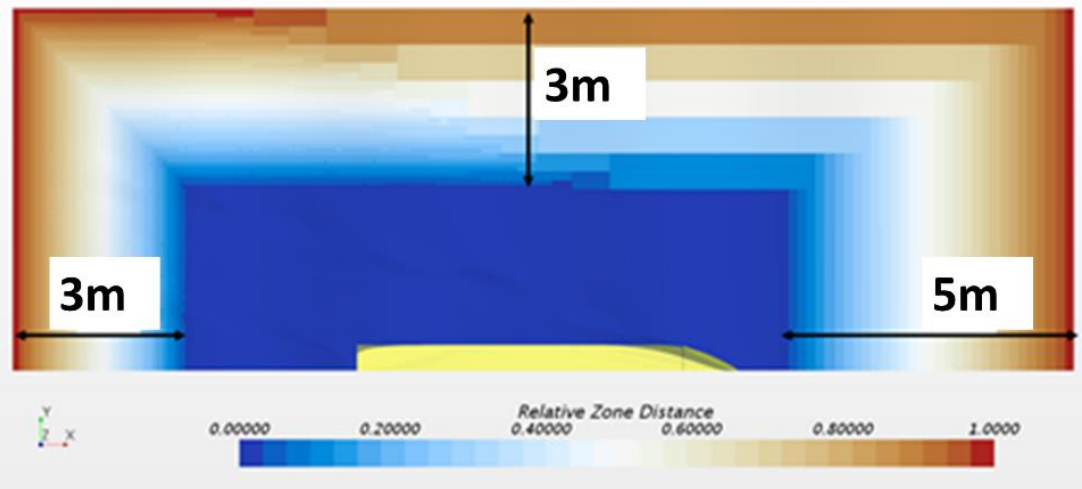

Fig. 3 Wave forcing length for added resistance in waves

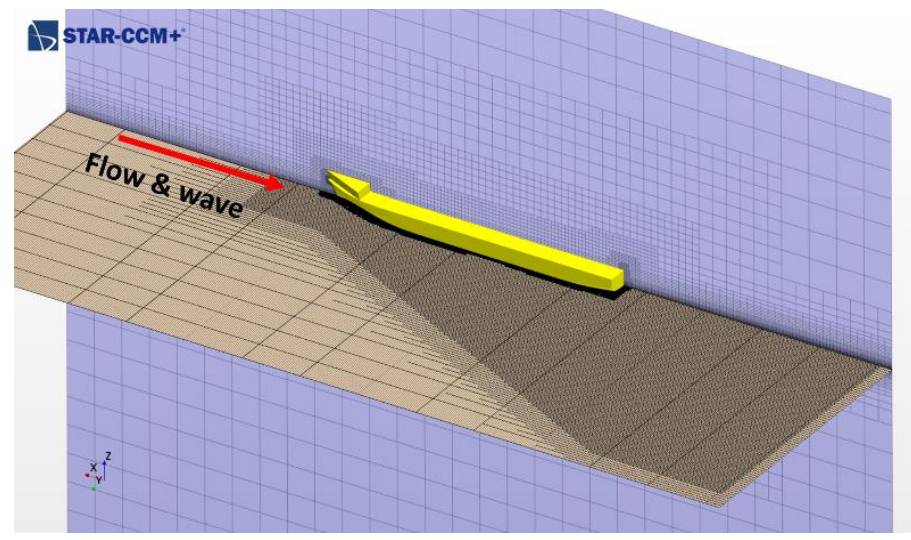

Fig. 4 Example volumetric mesh for added resistance in waves

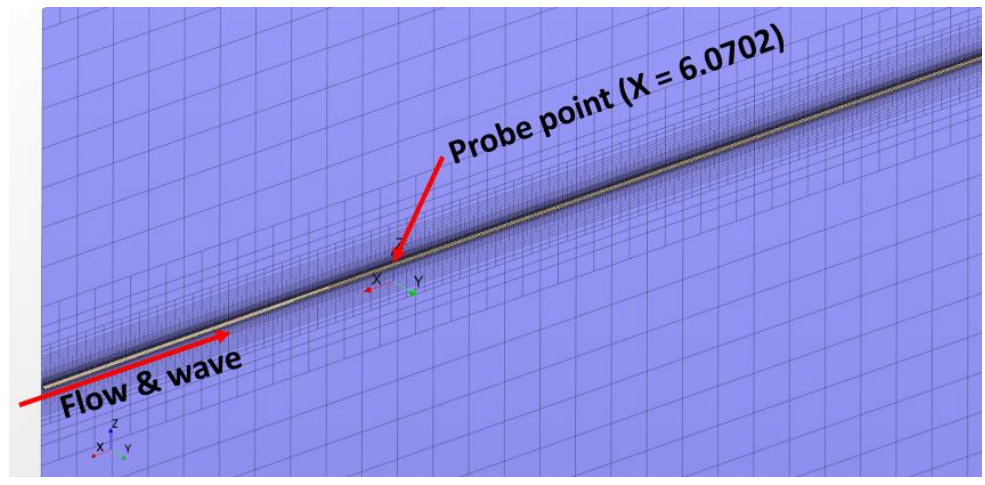

Fig. 5 Example 2.5D volumetric mesh without the hull for wave generation

\section{Simulation results}

\subsection{Resistance analysis results in calm condition}

Resistance analysis (Case 0) of KCS in the calm water condition was performed at the model ship speed of $2.006 \mathrm{~m} / \mathrm{s}$ and approximately 1.15 million grids were used. Fig. 6 and Table 6 represent the comparison between total resistance, trim and sinkage results obtained from the numerical simulation and the model test. Since STAR-CCM+ uses the right-handed coordinate system, positive sinkage means upward and the positive value of trim means when 
the bow part is lower than the stern part of the ship. The total resistance result obtained from numerical simulation is close to the model test result with a difference of around $2 \%$. On the other hand, both sinkage and trim results show about a $10 \%$ difference. It seems the $\mathrm{z}$ direction $(0.009 \mathrm{~m})$ size of the grid is comparatively large to compute changes in sinkage. If the $\mathrm{z}$-direction size of the grid is reduced by considering sink-age changes, it is expected to decrease the difference with the model test results.

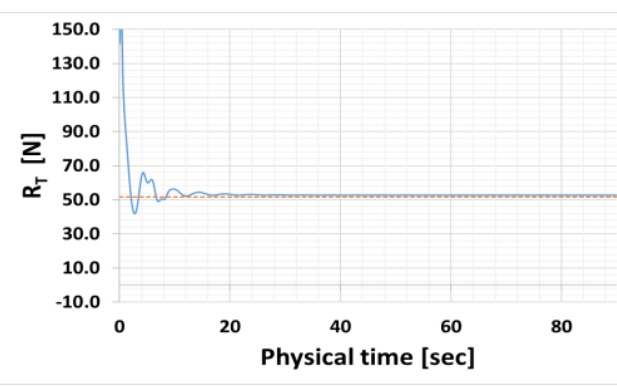

(a) Case 0 - total resistance

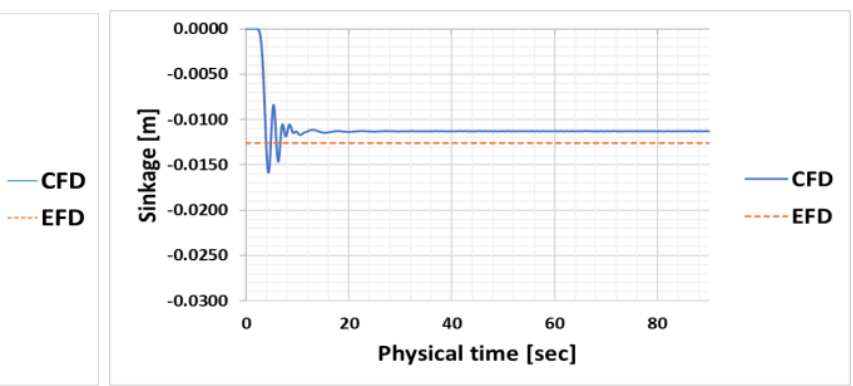

(b) Case 0 - Sinkage

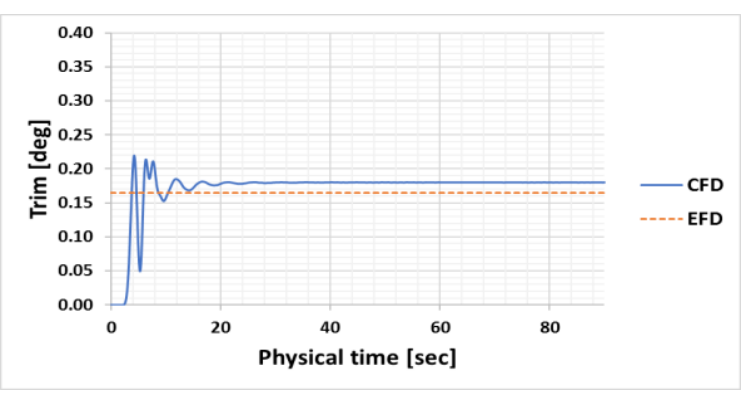

(c) Case 0 - Trim

Fig. 6 Comparison of total resistance, sinkage and trim with experimental data

Table 6 Total resistance, Sinkage and trim in calm water (Case 0)

\begin{tabular}{|c|c|c|c|}
\hline & EFD & CFD & Difference (\% with EFD) \\
\hline Total resistance $[\mathrm{N}]$ & 51.591 & 52.627 & -2.01 \\
\hline Sinkage $[\mathrm{m}]$ & -0.0126 & -0.0113 & 10.27 \\
\hline Trim $[\mathrm{deg})$ & 0.1646 & 0.1799 & -9.29 \\
\hline
\end{tabular}

* Difference with EFD is $(\mathrm{E}-\mathrm{S}) / \mathrm{E} \times 100$, where $\mathrm{E}$ is the $\mathrm{EFD}$ value, and $\mathrm{S}$ is the simulation value

\subsection{Comparison of waves and added resistance according to the presence of wave forcing}

The results according to the presence of wave forcing were compared with the results of Case 1. To prevent non-physical reflection at the boundary surface, wave damping was applied when wave forcing was not used and only applied at the outlet boundary for the added resistance analysis in waves. Wave damping length is from outlet boundary to LPP/2 which is $3 \mathrm{~m}$. When wave forcing is used, it is applied at the inlet, outlet and side boundary. The wave damping and wave forcing zones used for the added resistance analysis in wave are represented in Figs. 7 and 8.

Fig. 9 shows the measured time series values of the waves and the differences with the theoretical values are shown in Table 7. The location of measuring the generated waves is FP (Forward Perpendicular) of KCS when there is no ship hull and the wave height changes with 
time were measured when the crest of the generated wave is located at FP for the accuracy of the waves.

From the results shown in Fig. 9 and Table 7, the difference due to the presence of wave forcing is not large when there is no ship. However, when there is a ship hull and wave forcing is applied, the wave approaching the ship hull seems to be excessively disturbed by the reflected waves by ship hull. In addition to that, the total resistance and motion response results showed continuous oscillation with a long period as shown in Fig. 10. Therefore, this research studied on the added resistance and the motion response with applying wave forcing method.

Table 7 Wave amplitude in wave conditions regard with and without wave forcing

\begin{tabular}{|c|c|c|c|c|c|}
\hline \multirow{2}{*}{} & \multicolumn{3}{|c|}{ Stokes' 5th order wave } & \multicolumn{2}{c|}{ Difference (\% with theory) } \\
\cline { 2 - 6 } & Theory & $\begin{array}{c}\text { CFD with } \\
\text { wave forcing }\end{array}$ & $\begin{array}{c}\text { CFD w/o } \\
\text { wave forcing }\end{array}$ & $\begin{array}{c}\text { CFD with } \\
\text { wave forcing }\end{array}$ & $\begin{array}{c}\text { CFD w/o wave } \\
\text { forcing }\end{array}$ \\
\hline Crest & 0.03174 & 0.03145 & 0.03208 & 0.93 & -1.07 \\
\hline Trough & -0.03021 & -0.03007 & -0.02963 & 0.47 & 1.92 \\
\hline
\end{tabular}

* Difference with theory is $(\mathrm{T}-\mathrm{S}) / \mathrm{T} \times 100$, where $\mathrm{T}$ is the theory value, and $\mathrm{S}$ is the simulation value

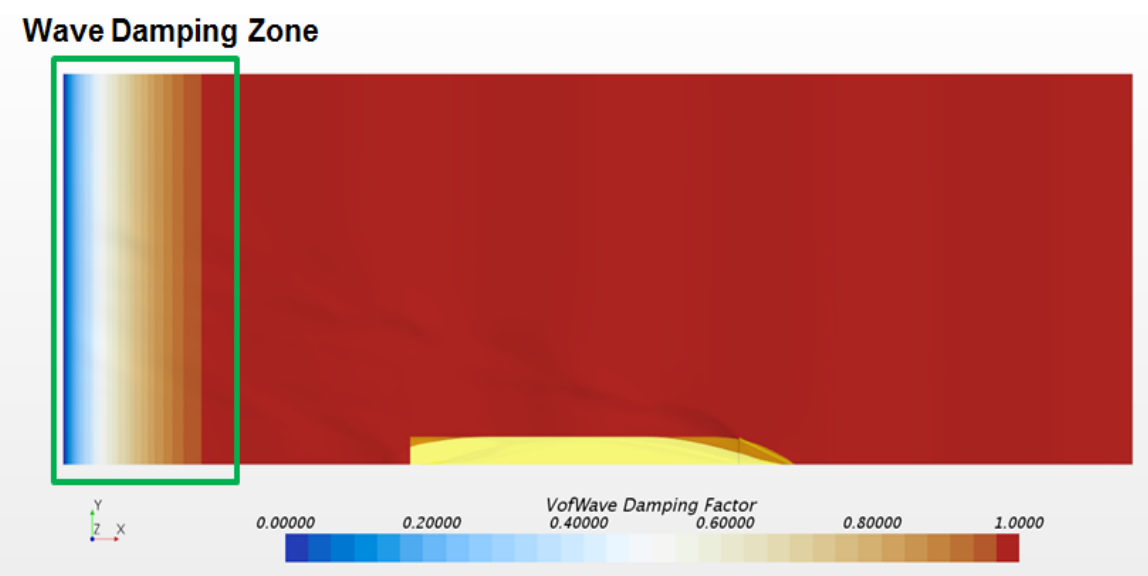

Fig. 7 Wave damping zone for added resistance in wave condition

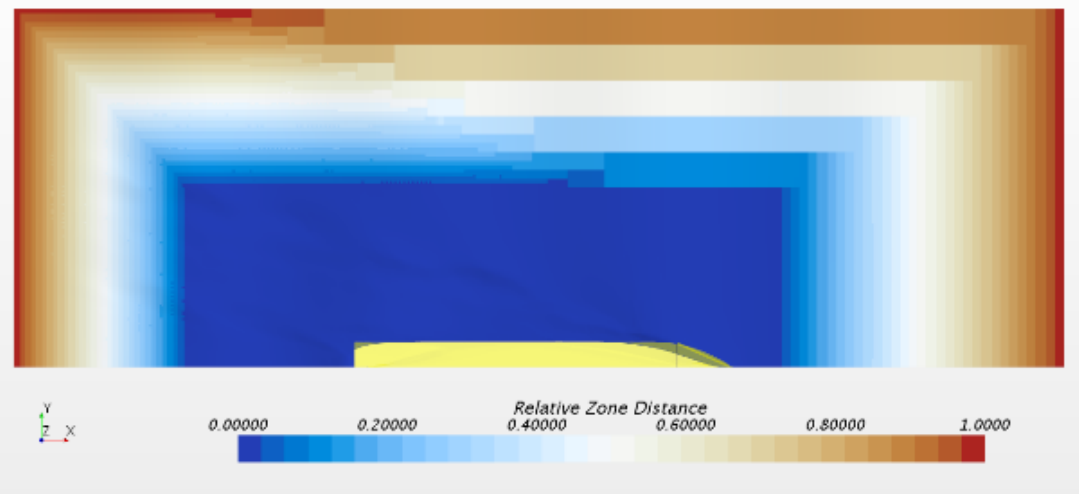

Fig. 8 Wave forcing zone for added resistance in wave condition 


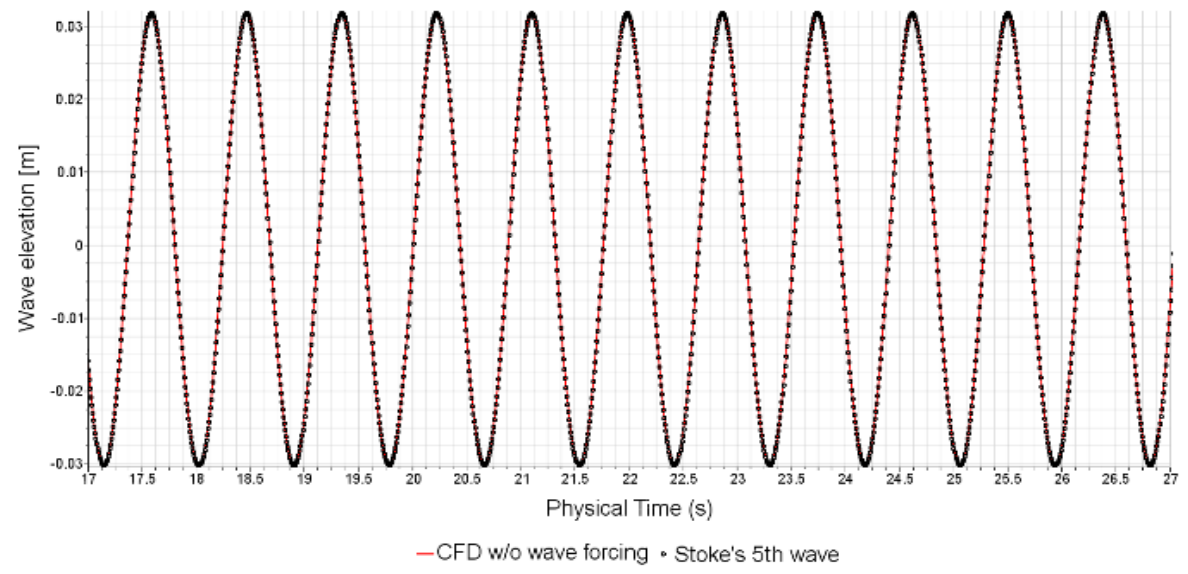

(a) Without wave forcing

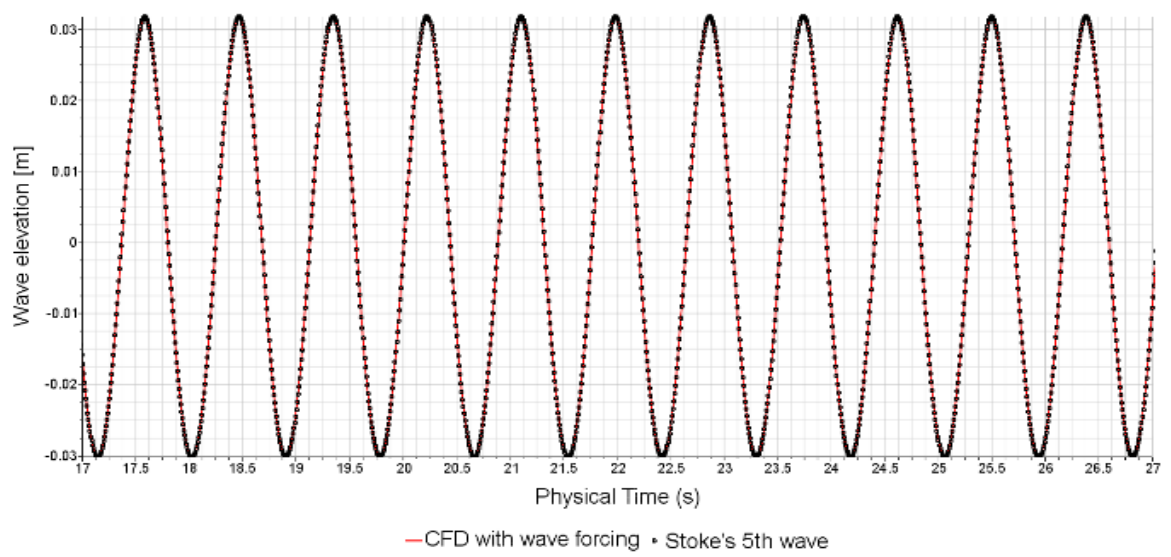

(b) With wave forcing

Fig. 9Time history of wave elevation with and without wave forcing

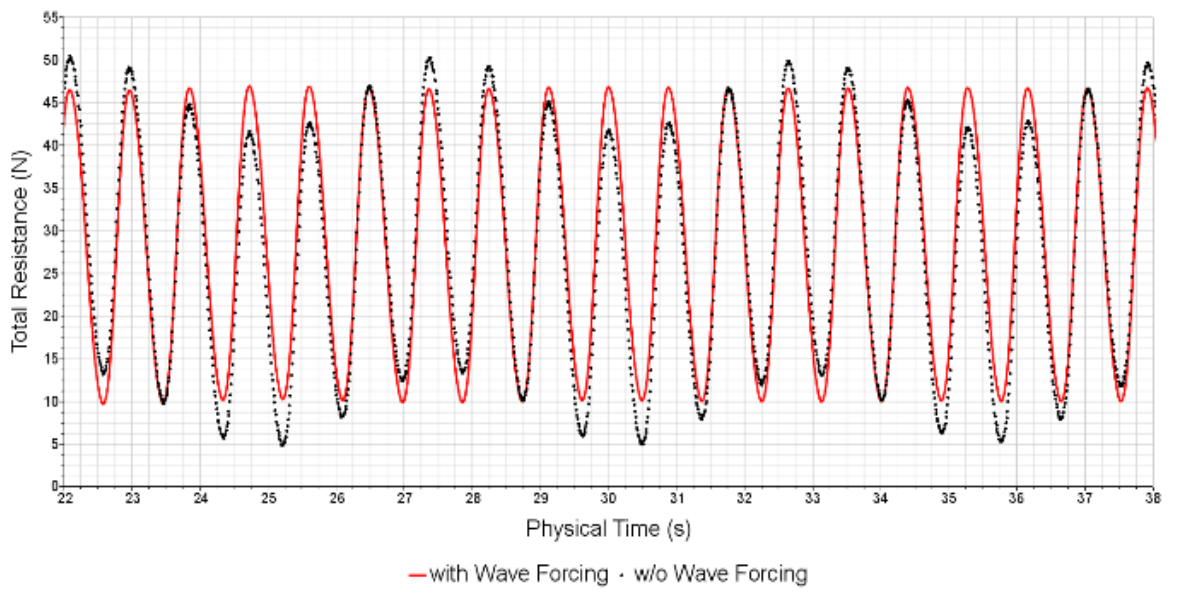

(a) Total resistance 


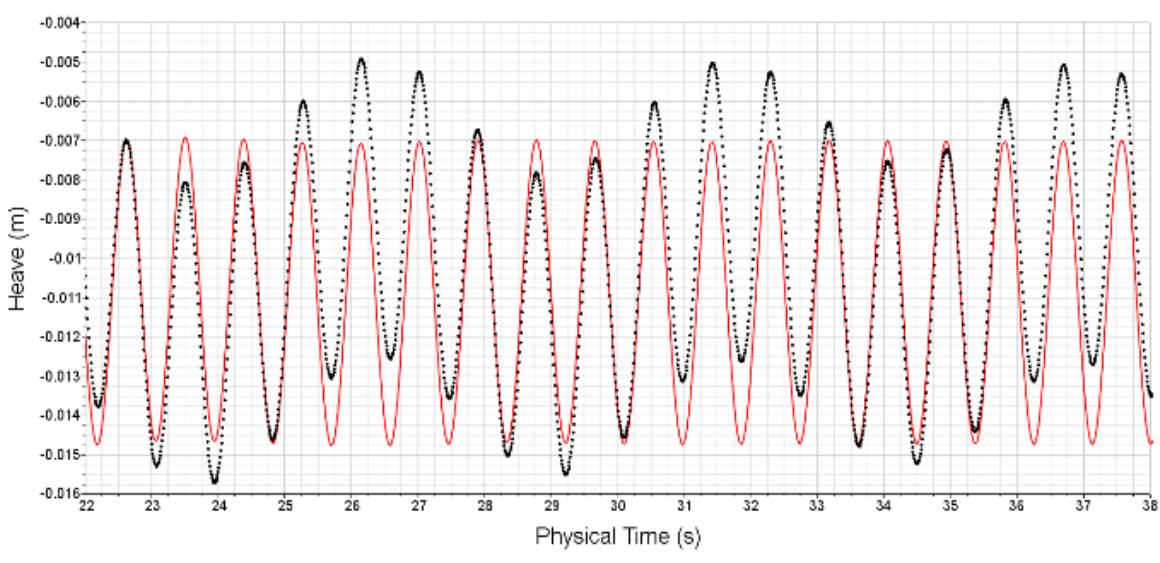

- with Wave Forcing · w/o Wave Forcing

(b) Heave

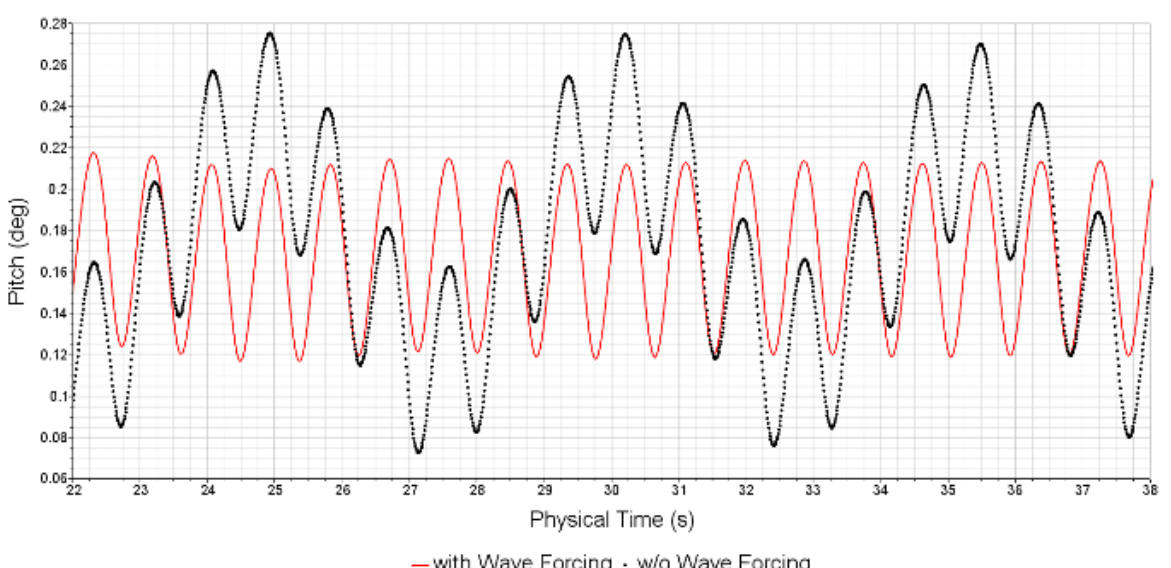

(c) Pitch

Fig. 10 Comparison of total resistance, heave and pitch with and without wave forcing

\subsection{Wave generation results}

Applying wave forcing, the location of measurement for the generated waves is FP (Forward Perpendicular) of KCS when there is no ship hull and the wave height changes with time were measured when the crest of the generated wave is located at FP for the accuracy of waves. To judge the accuracy of the waves, the simulation results of waves progressing for 10 periods after 20 periods were compared with the theoretical values of the waves. 


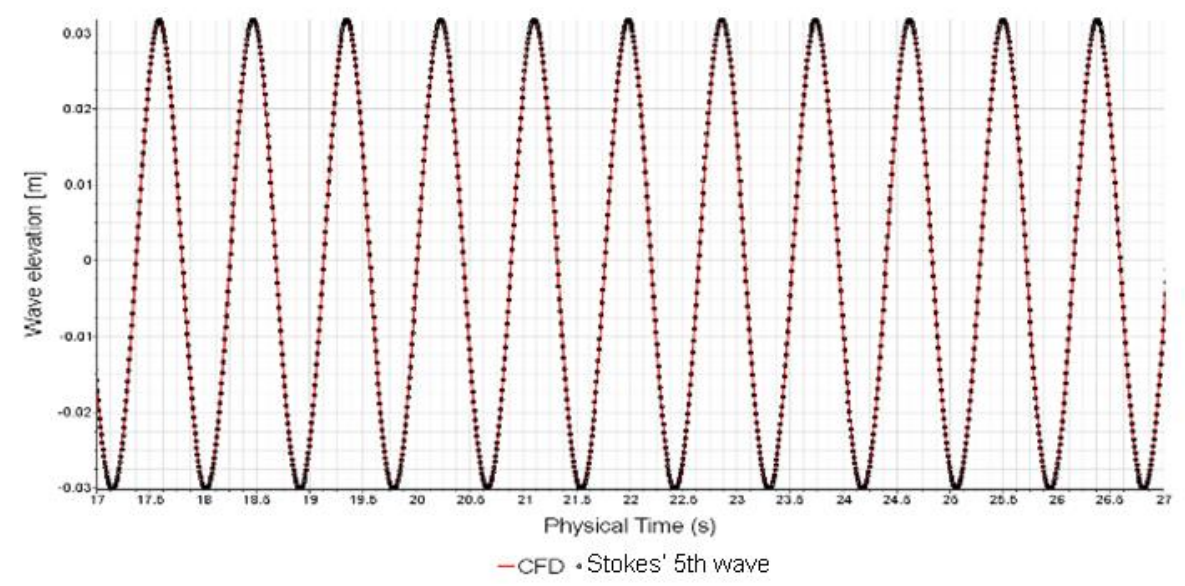

(a) Case $1(\lambda / \mathrm{LPP}=0.65)$

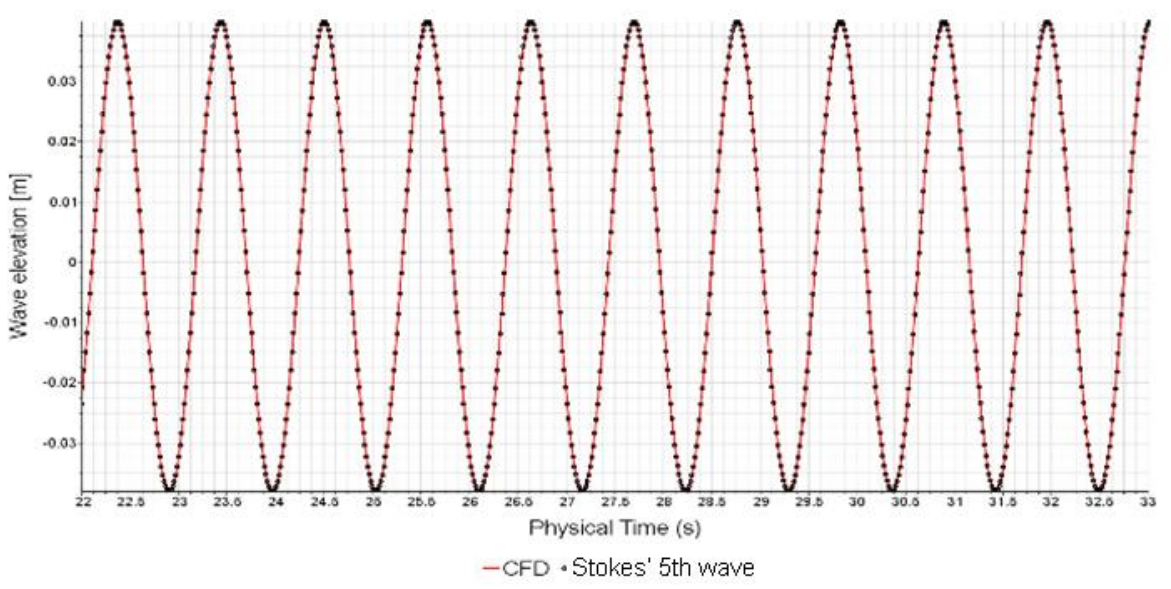

(b) Case $2\left(\lambda / L_{P P}=0.85\right)$

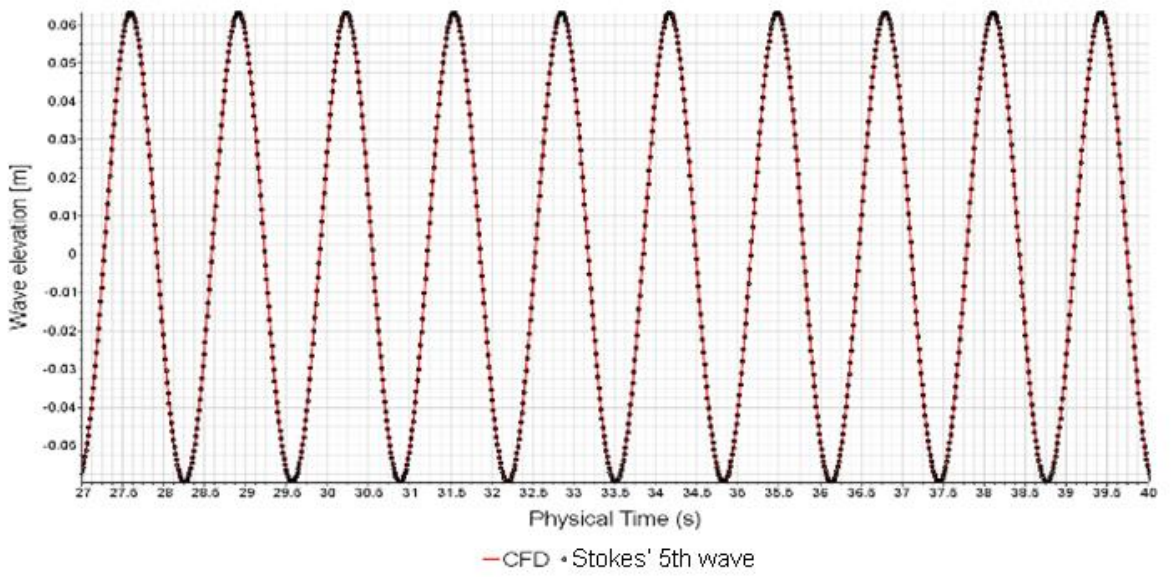

(c) Case $3(\lambda / \mathrm{LPP}=1.15)$ 
Young-Gill Lee, Cheolho Kim, Jeong-Ho Park , Hyeongjun Kim, Insu Lee, Bongyong Jin
Numerical simulations of added resistance in regular head waves on a container ship

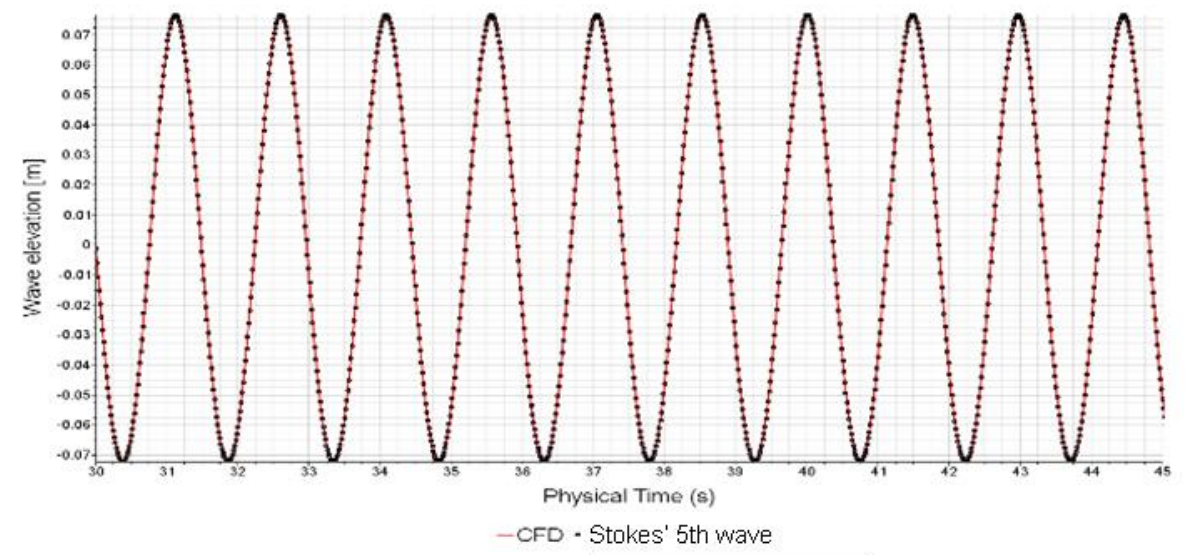

(d) Case $4\left(\lambda / L_{P P}=1.37\right)$

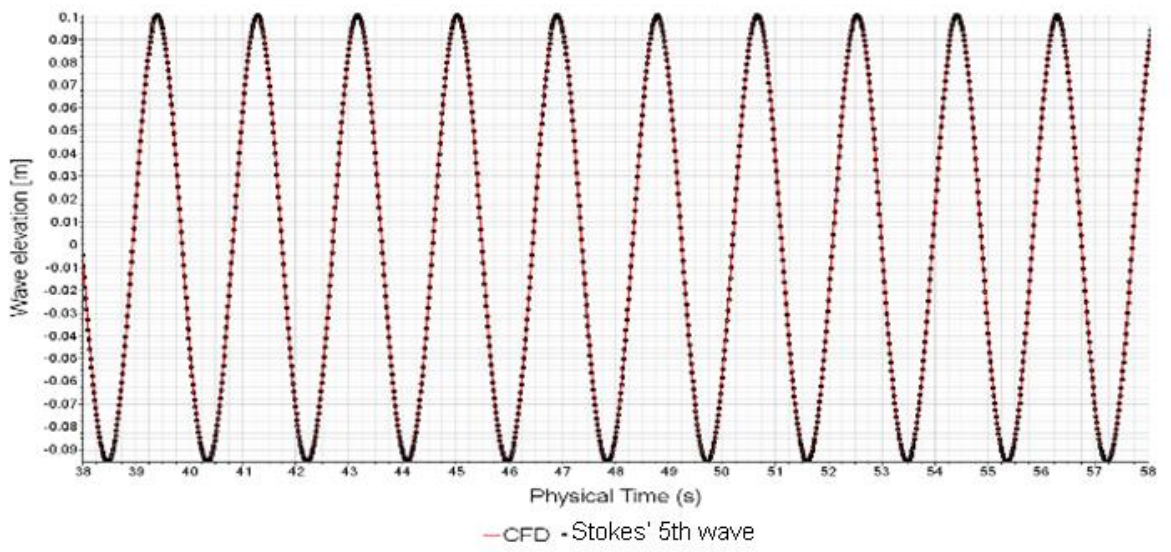

(e) Case $5\left(\lambda / L_{P P}=1.95\right)$

Fig. 21 Time history of wave elevation under wave conditions

Table 8 Wave amplitude in wave conditions

\begin{tabular}{|c|c|c|c|c|}
\hline \multirow{2}{*}{\multicolumn{2}{|c|}{ Case no. }} & \multicolumn{2}{|c|}{ Stokes' 5th-order wave } & \multirow{2}{*}{$\begin{array}{c}\text { Difference }(\% \text { with } \\
\text { theory) }\end{array}$} \\
\hline & & Theory & CFD & \\
\hline \multirow{2}{*}{1} & Crest & 0.03174 & 0.03145 & 0.93 \\
\hline & Trough & -0.03021 & -0.03007 & 0.47 \\
\hline \multirow{2}{*}{2} & Crest & 0.03991 & 0.03978 & 0.34 \\
\hline & Trough & -0.03806 & -0.03794 & 0.32 \\
\hline \multirow{2}{*}{3} & Crest & 0.06316 & 0.06320 & -0.01 \\
\hline & Trough & -0.05975 & -0.05957 & 0.35 \\
\hline \multirow{2}{*}{4} & Crest & 0.07656 & 0.07652 & 0.05 \\
\hline & Trough & -0.07236 & -0.07205 & 0.43 \\
\hline \multirow{2}{*}{5} & Crest & 0.10053 & 0.10057 & -0.04 \\
\hline & Trough & -0.09542 & -0.09513 & 0.31 \\
\hline
\end{tabular}

* Difference with theory is (T-S)/T $\times 100$, where $\mathrm{T}$ is the theory value, and $\mathrm{S}$ is the simulation value 


\subsection{Added resistance analysis results in waves}

For the added resistance analysis, the regular waves shown in Table 3 were input. CFD calculation result of total resistance, pitch and heave motion RAO are shown in Fig. 12-14. Overall 5 cases, after 20 encounter periods, numerical results have their repeatability. Considering the accuracy of the waves, the average of the numerical simulation results over 10 periods after 20 were compared with the experimental results. Fig. 15-17 show the total resistance and motions of the ship, and Table 9 compares the simulation results of the total resistance with the 1 period average of the experimental results. Te in Figs. 15-17 is the encounter period, $\zeta_{\mathrm{s}}$ is the wave amplitude, $\mathrm{k}$ is the wave number and $\theta$ is the pitching angle which is expressed in radians. Since the average was provided for Case 3 instead of time series values due to the resonance period during the experiments, the simulation result was also compared by taking the average of the values.

From the total resistance results of Cases 1-5, the overall results are qualitatively similar to the experimental results except for Case 2. The difference between the total resistance with wave period in Table 9 and the experimental values is less than $4 \%$. Heave and pitch results also show differences in Case 2 but are generally similar to the experimental results (Figs.1517).

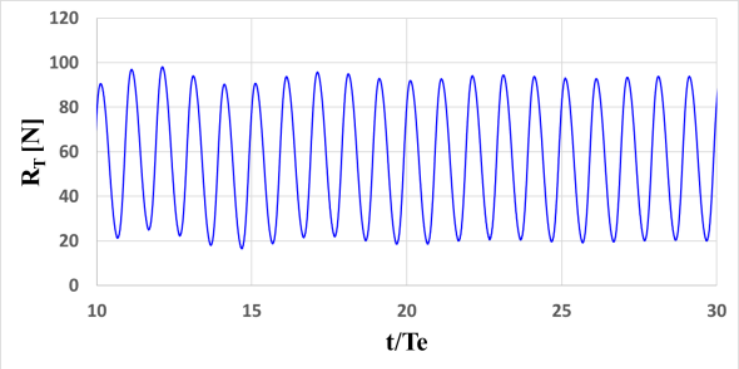

(a) Case $1\left(\lambda / L_{P P}=0.65\right)$

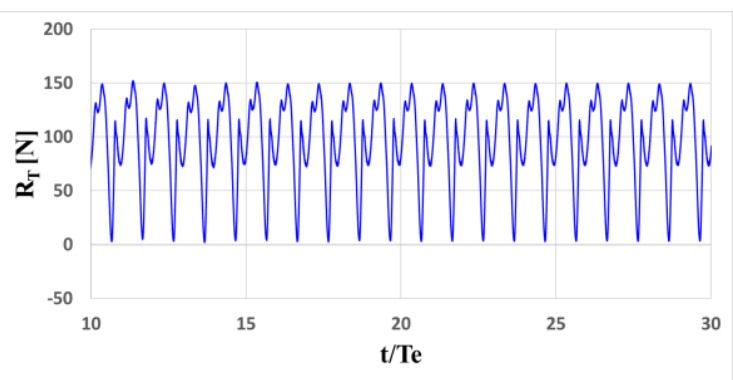

(c) Case $3\left(\lambda / L_{P P}=1.15\right)$

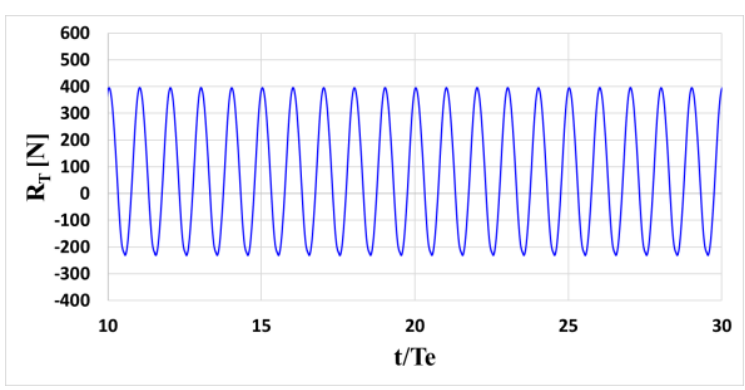

(e) Case $5\left(\lambda / L_{P P}=1.95\right)$

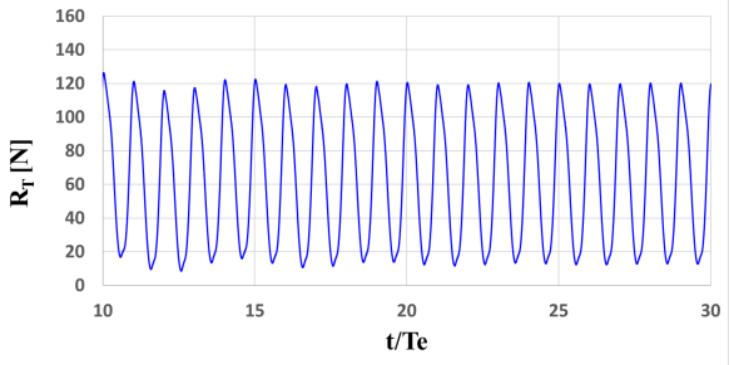

(b) Case $2\left(\lambda / \mathrm{L}_{\mathrm{PP}}=0.85\right)$

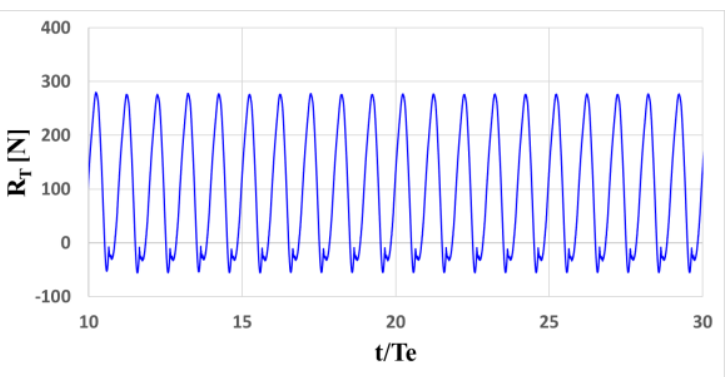

(d) Case $4\left(\lambda / L_{P P}=1.37\right)$

Fig. 32 Time history of total resistance in wave conditions from 10 to 30 encounter period of CFD result 


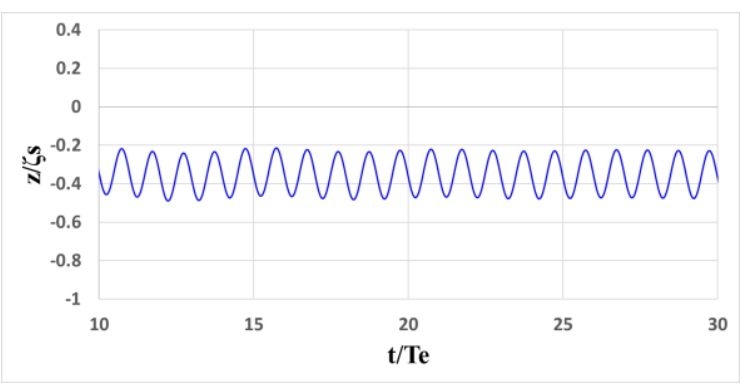

(a) Case $1\left(\lambda / L_{P P}=0.65\right)$

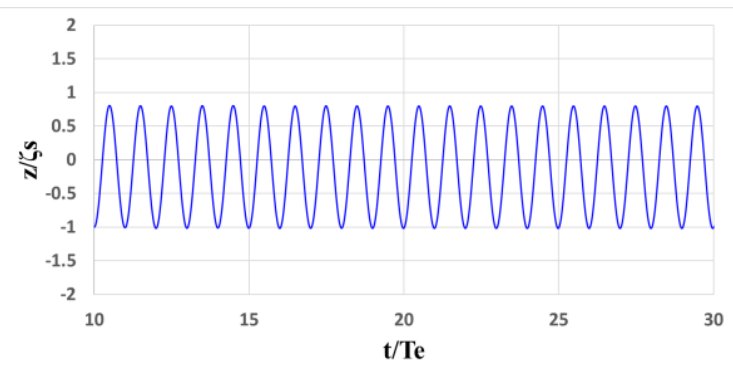

(c) $\operatorname{Case} 3\left(\lambda / L_{P P}=1.15\right)$

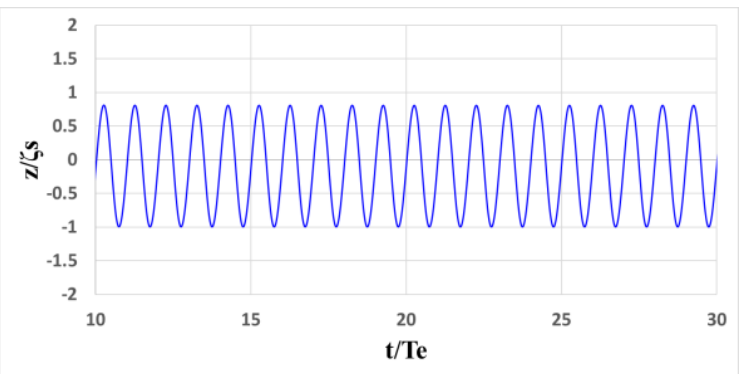

(e) Case $5\left(\lambda / L_{P P}=1.95\right)$

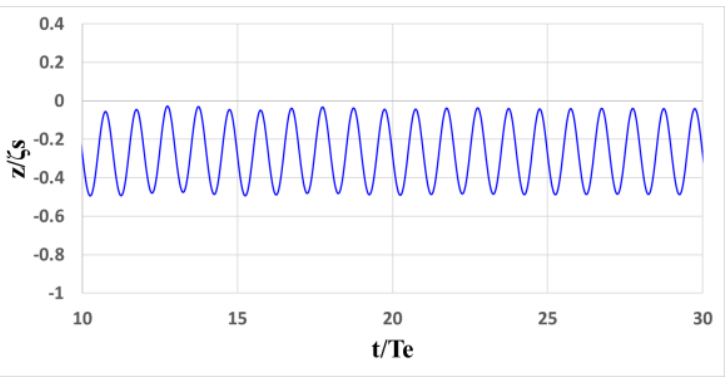

(b) Case $2\left(\lambda / \mathrm{L}_{\mathrm{PP}}=0.85\right)$

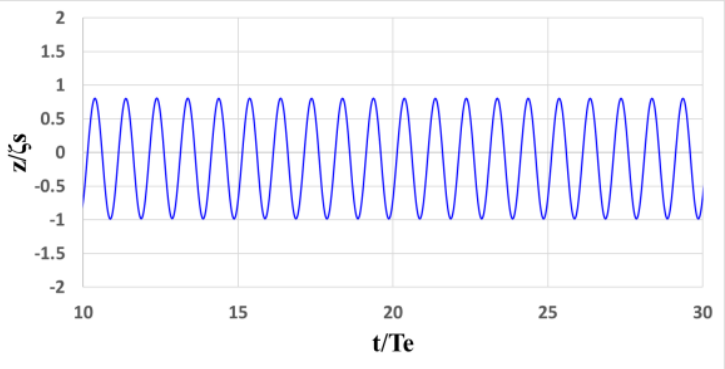

(d) Case $4\left(\lambda / L_{P P}=1.37\right)$

Fig. 43 Time history of heave motion in wave conditions from 10 to 30 encounter period of CFD result

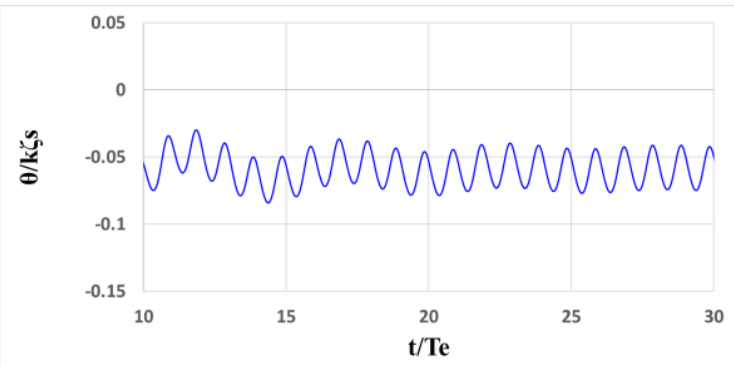

(a) Case $1\left(\lambda / L_{P P}=0.65\right)$

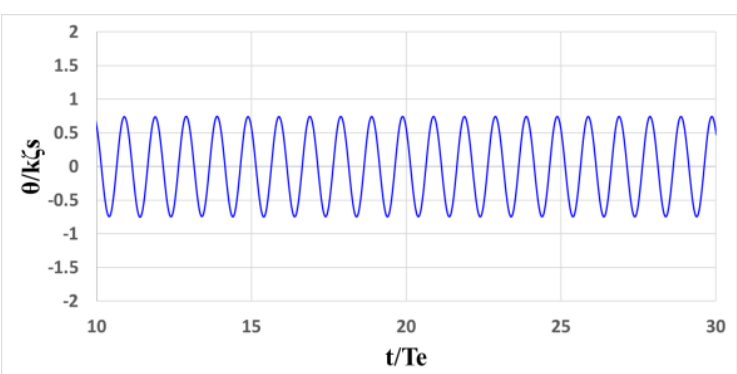

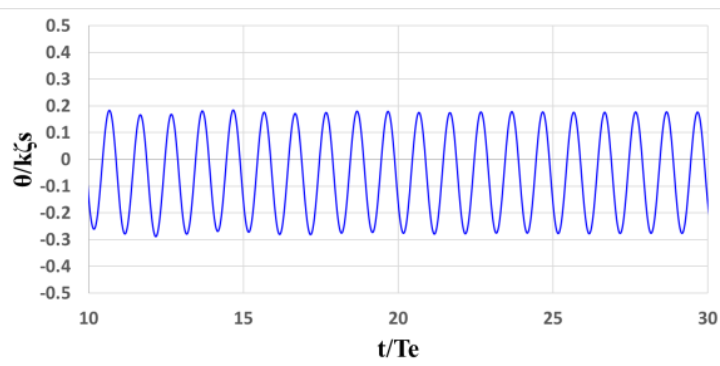

(b) Case $2\left(\lambda / \mathrm{L}_{\mathrm{PP}}=0.85\right)$

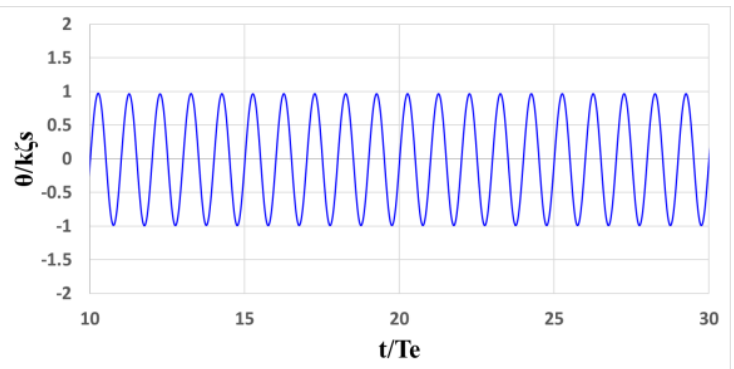


Numerical simulations of added resistance in regular head waves on a container ship
Young-Gill Lee, Cheolho Kim, Jeong-Ho Park Hyeongjun Kim, Insu Lee, Bongyong Jin
(c) Case $3\left(\lambda / L_{P P}=1.15\right)$
(d) Case $4\left(\lambda / L_{P P}=1.37\right)$

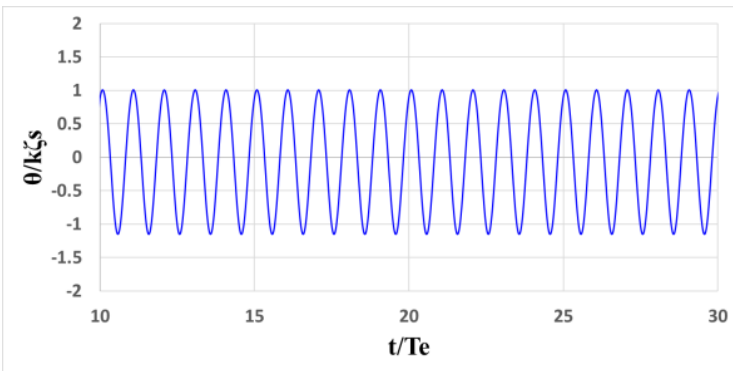

(e) $\operatorname{Case} 5\left(\lambda / L_{P P}=1.95\right)$

Fig. 54 Time history of pitch motion in wave conditions from 10 to 30 encounter period of CFD result

Table 9 Total resistance in wave conditions

\begin{tabular}{|c|c|c|c|}
\hline \multirow{2}{*}{ Case no. } & \multicolumn{2}{|c|}{ Total resistance [N] } & \multirow{2}{*}{ Difference (\% with EFD) } \\
\cline { 2 - 3 } & EFD & CFD & -1.38 \\
\hline 1 & 55.748 & 56.514 & -0.09 \\
\hline 2 & 62.353 & 62.407 & -0.94 \\
\hline 3 & 95.218 & 96.119 & -3.83 \\
\hline 4 & 94.572 & 98.191 & 2.63 \\
\hline 5 & 76.196 & 74.191 & \\
\hline
\end{tabular}

* Difference with EFD is $(\mathrm{E}-\mathrm{S}) / \mathrm{E} \times 100$, where $\mathrm{E}$ is the $\mathrm{EFD}$ value, and $\mathrm{S}$ is the simulation value

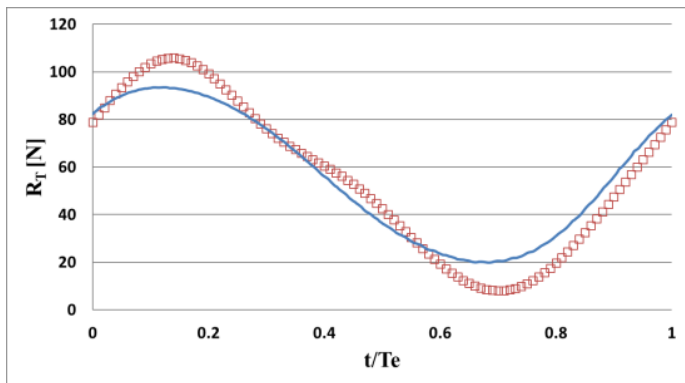

(a) Case $1\left(\lambda / L_{P P}=0.65\right)$

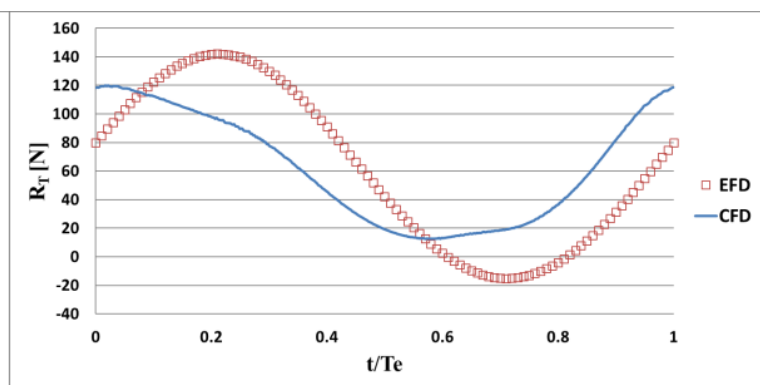

(b) Case $2\left(\lambda / \mathrm{LPP}_{\mathrm{PP}}=0.85\right)$

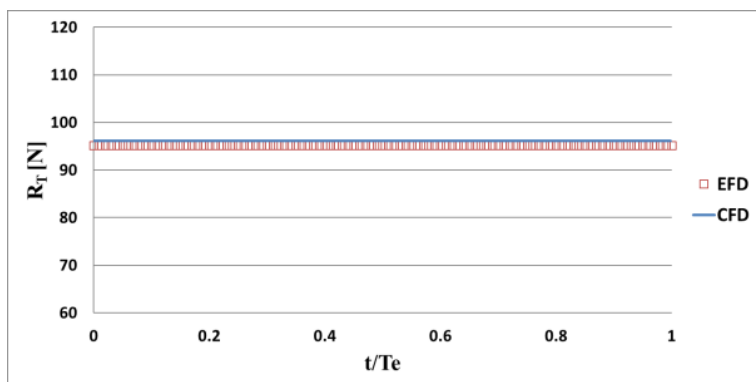

(c) Case $3\left(\lambda / L_{P P}=1.15\right)$, mean value of total resistance

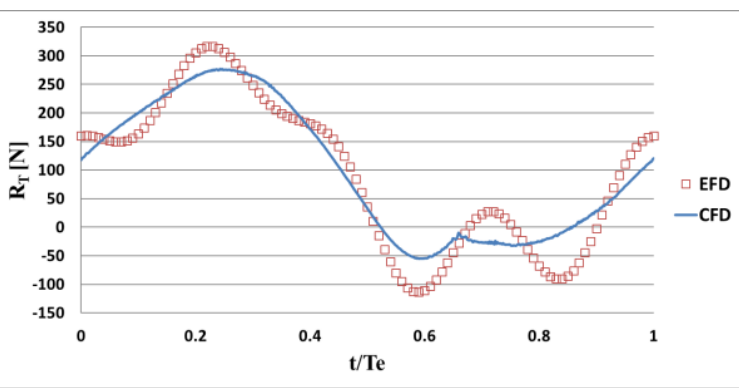

(d) Case $4\left(\lambda / L_{P P}=1.37\right)$ 
Young-Gill Lee, Cheolho Kim, Jeong-Ho Park , Hyeongjun Kim, Insu Lee, Bongyong Jin
Numerical simulations of added resistance in regular head waves on a container ship

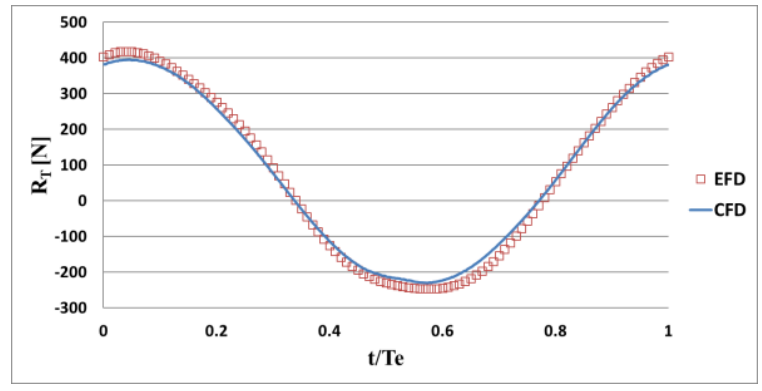

(e) Case $5\left(\lambda / L_{P P}=1.95\right)$

Fig. 65 Time history of total resistance in wave conditions

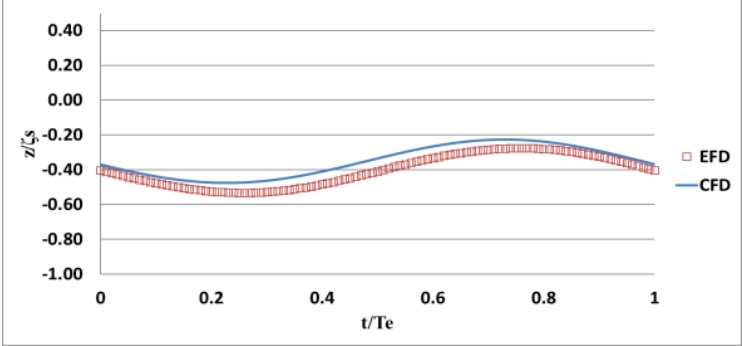

(a) Case $1\left(\lambda / \mathrm{L}_{\mathrm{PP}}=0.65\right)$

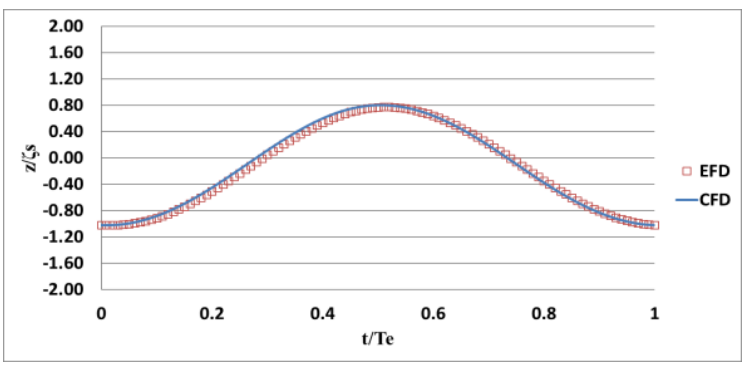

(c) Case $3\left(\lambda / L_{P P}=1.15\right)$

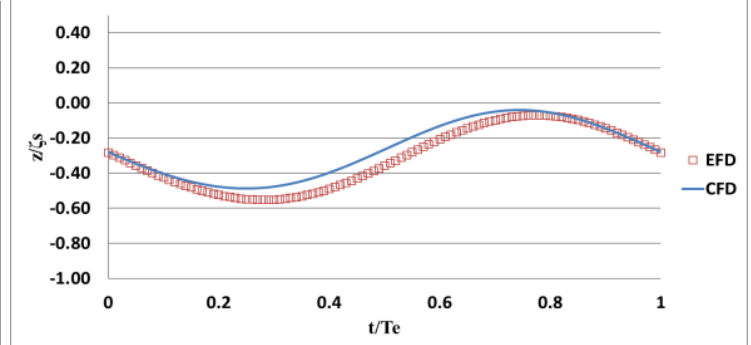

(b) Case $2\left(\lambda / L_{P P}=0.85\right)$

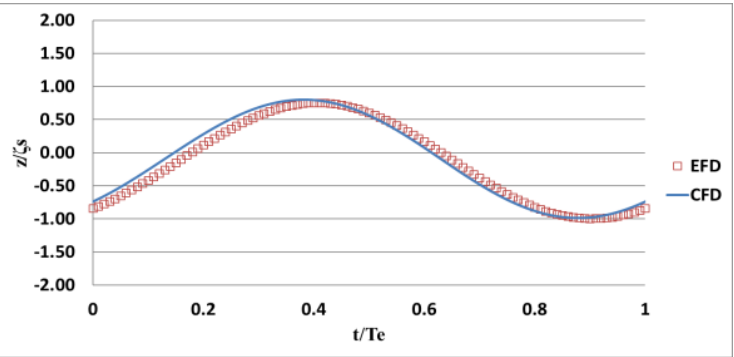

(d) Case $4\left(\lambda / L_{P P}=1.37\right)$

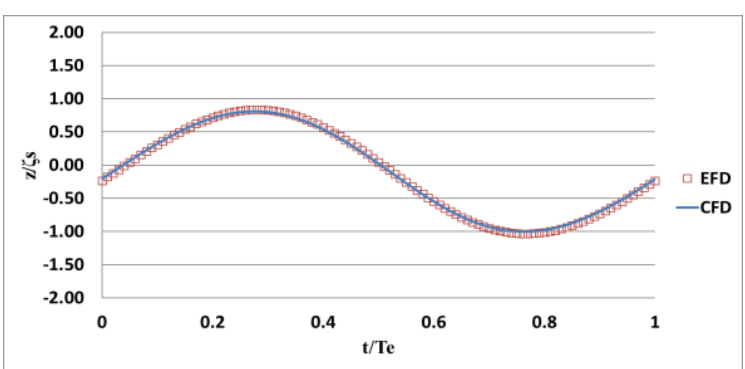

(e) Case $5\left(\lambda / L_{P P}=1.95\right)$

Fig. 76 Time history of heave motion in wave conditions 


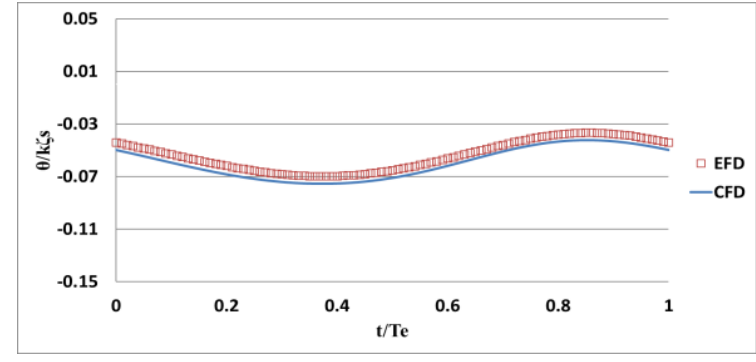

(a) Case $1\left(\lambda / L_{P P}=0.65\right)$

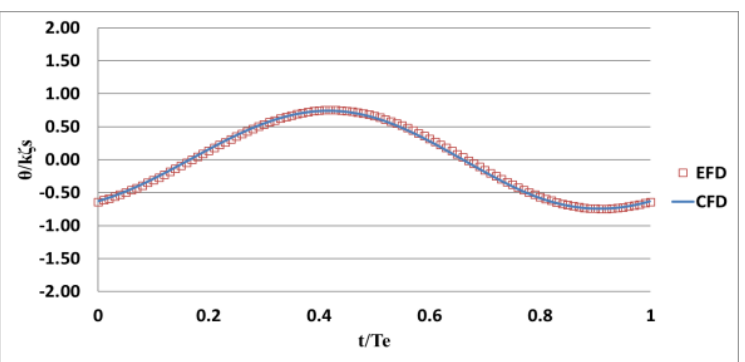

(c) Case $3\left(\lambda / L_{P P}=1.15\right)$

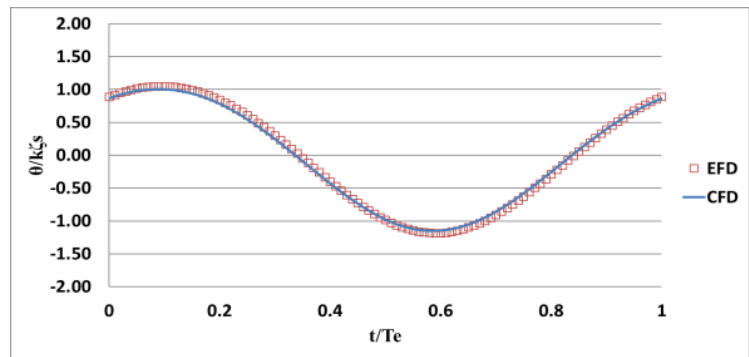

(e) Case $5\left(\lambda / L_{P P}=1.95\right)$

Fig. 87 Time history of pitch motion in wave conditions

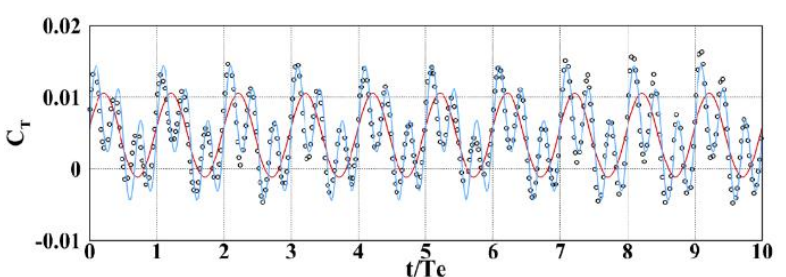

(a) Force

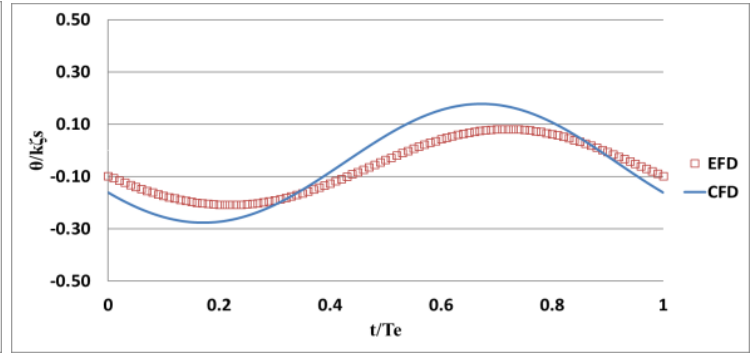

(b) Case $2\left(\lambda / L_{P P}=0.85\right)$

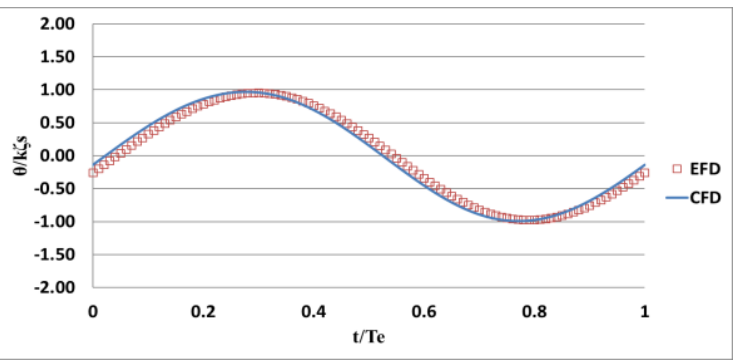

(d) Case $4\left(\lambda / L_{P P}=1.37\right)$

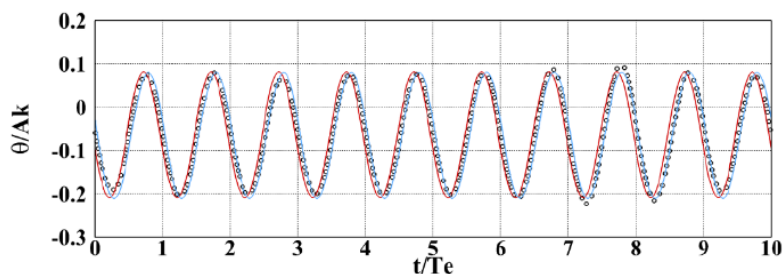

(b) Pitch

Fig. 98 Time series for force and pitch of KCS in regular heading wave at Case 2 for EFD (symbol), reconstructed based on T2015 values (FORCE: red line) and reconstructed based on current values (blue line)

Fig. 18 shows the reconstructed total resistance and pitch motion from experimental values. The difference between Fig.15 (b) and Fig.17 (b) is considered to take place when reconstructing the values.

The transfer functions of those motions can be defined as Equation (6) and (7).

$$
\begin{aligned}
& T F_{3}=\zeta_{3} / A \\
& T F_{5}=\zeta_{5} / k A
\end{aligned}
$$


$\zeta_{3}, \zeta_{5}$ and A denote the amplitude of the first harmonic function of the heave, pitch motion and incident wave amplitude respectively and $k$ means wave number.

Non-dimensional equation of the added resistance is defined as Equation (8).

$$
C_{\mathrm{aw}}=\frac{\left(F_{\mathrm{Wave}}-F_{\mathrm{calm}}\right)}{\rho g \zeta^{2}{ }_{\mathrm{I}} B^{2} \mathrm{WL} / L_{P P}}
$$

In the equation (8), $F_{\text {wave }}$ means the time average value of resistance in the wave, and $F_{\text {calm }}$ denotes the resistance in calm water condition.

Tables 10 and 11 compare the simulation and experiment result of the heave and pitch RAO (Response Amplitude Operator). Except for Case 2, the difference in heave and pitch RAO with wave period is less than $5 \%$. The simulation results are confirmed to be similar to the experimental results (Fig. 19). The added resistance was compared in Table 12 and the differences between experiment and simulation were less than $10 \%$. Case 5 where the wave length is about 2 times of the ship length showed the largest difference of approximately $12 \%$. This result can also be found in Fig. 19 (c). In Case 3, which corresponded to resonance domain, the difference was slight, about $0.3 \%$. Also, to judge of tendencies for the heave RAO, pitch RAO and the added resistance coefficient, only simulation results of 0.4 and 2.1 in $\lambda /$ Lpp had added. These results are shown in Tables 10-12 and Fig. 19.

Table 10 Heave RAO

\begin{tabular}{|c|c|c|c|c|}
\hline \multirow{2}{*}{ Case } & \multirow{2}{*}{$\lambda /$ LPP } & \multicolumn{2}{|c|}{$T F_{3}$} & \multirow{2}{*}{ Difference (\% with EFD) } \\
\cline { 3 - 5 } & & EFD & CFD & \\
\hline & 0.40 & & 0.007 & 4.3 \\
\hline 1 & 0.65 & 0.130 & 0.124 & 8.5 \\
\hline 2 & 0.85 & 0.244 & 0.223 & -1.1 \\
\hline 3 & 1.15 & 0.899 & 0.909 & -2.3 \\
\hline 4 & 1.37 & 0.874 & 0.894 & 3.3 \\
\hline 5 & 1.95 & 0.933 & 0.902 & \\
\hline & 2.10 & & 0.925 & \\
\hline
\end{tabular}

* Difference with EFD is $(\mathrm{E}-\mathrm{S}) / \mathrm{E} \times 100$, where $\mathrm{E}$ is the $\mathrm{EFD}$ value, and $\mathrm{S}$ is the simulation value

Table 11 Pitch RAO

\begin{tabular}{|c|c|c|c|c|}
\hline \multirow{2}{*}{ Case } & \multirow{2}{*}{$\lambda /$ LPP } & \multicolumn{2}{|c|}{$T F_{5}$} & \multirow{2}{*}{ Difference (\% with EFD) } \\
\cline { 3 - 4 } & & EFD & CFD & \\
\hline & 0.40 & & 0.009 & 4.3 \\
\hline 1 & 0.65 & 0.017 & 0.016 & -55.3 \\
\hline 2 & 0.85 & 0.146 & 0.227 & 0.5 \\
\hline 3 & 1.15 & 0.748 & 0.744 & -1.2 \\
\hline 4 & 1.37 & 0.966 & 0.978 & 3.7 \\
\hline 5 & 1.95 & 1.120 & 1.079 & \\
\hline & 2.10 & & 1.076 & \\
\hline
\end{tabular}


Table 12 Added resistance coefficient in waves

\begin{tabular}{|c|c|c|c|c|}
\hline \multirow{2}{*}{ Case } & \multirow{2}{*}{$\lambda /$ LPP } & \multicolumn{2}{|c|}{$C_{\text {aw }} \times 10^{3}$} & \multirow{2}{*}{ Difference (\% with EFD) } \\
\cline { 3 - 5 } & & EFD & CFD & \\
\hline & 0.40 & & 3.994 & 6.47 \\
\hline 1 & 0.65 & 3.671 & 3.433 & 9.12 \\
\hline 2 & 0.85 & 6.005 & 5.457 & 0.31 \\
\hline 3 & 1.15 & 9.790 & 9.760 & -6.01 \\
\hline 4 & 1.37 & 6.572 & 6.967 & 12.36 \\
\hline 5 & 1.95 & 2.174 & 1.905 & \\
\hline & 2.10 & & 1.400 & \\
\hline
\end{tabular}

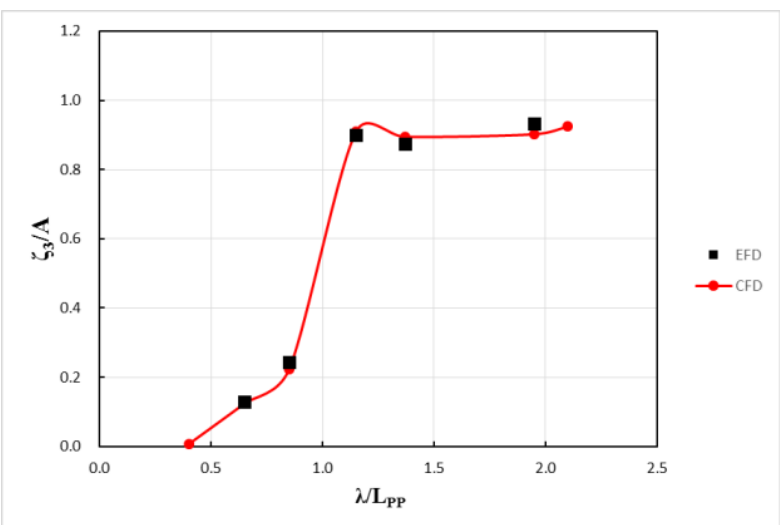

(a) Heave motion

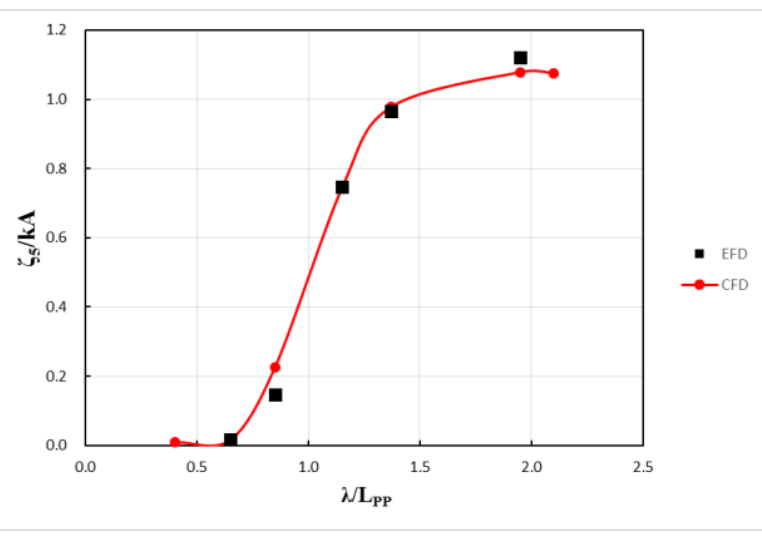

(b) Pitch motion

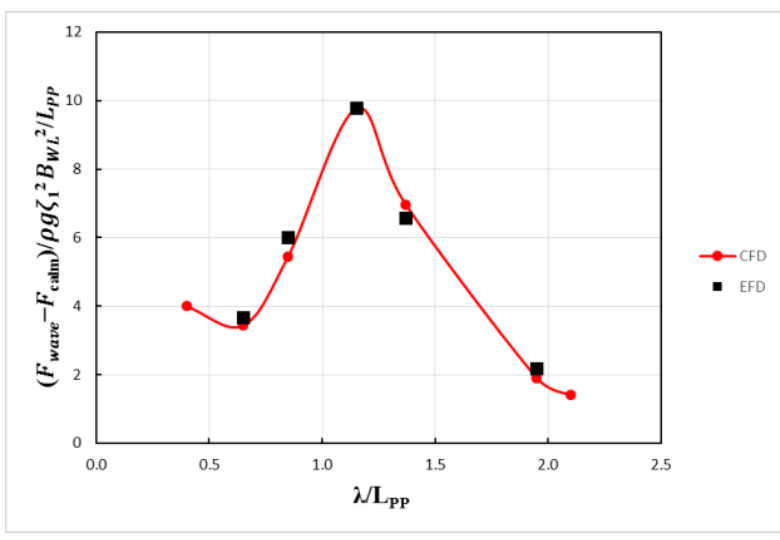

(c) Added resistance coefficient

Fig. 109 Motion RAO and added resistance coefficient under different wave conditions

The proportion of average pressure and shear force in the average of the total resistance is compared in Table 13. Shear force is more dominant in the low period domain. On the other hand, pressure is dominant in the resonance domain. When taking a look at changes in pressure and shear force, the change in pressure due to wave length is larger than that of shear force. 
Fig. 20 shows the time history of pressure and shear force in waves over one encounter period. The pressure components of Cases 1,2 and 5 show a sinusoidal wave form, but the different shapes are shown in Cases 3 and 4. The moments when the pressure distribution acting on the hull in Cases 3 and 4 turn non-linear are shown in Figs. 21 and 22 in order to identify the causes of the difference in the shape of the time series.

Fig. 21 shows the pressure distribution on the ship surface when the $t / T e$ value changes from 0.7 to 0.8 of Case 3 in Fig. 20(c). Fig. 22 shows the pressure distribution on the ship surface when the t/Te value changes from 0.6 to 0.7 of Case 4 in Fig. 20(d). When the pressure non-linearly increases, the impact form of pressure change can be seen at the knuckle located at the bow height of the deck. The high local pressure is acting at the end of the bow while the incoming crest encounters the bow. The impact and the high local pressure acting on the bow are the cause of a change in pressure that is larger than the changes in shear force in the resonance domain. The high pressure acting on the hull is caused at the knuckle and the bow above the waterline (Figs. 21 and 22). Therefore, if the bow shape above the waterline is improved, added resistance will be reduced.

Table 13 Average values of the resistance due to pressure and shear in waves

\begin{tabular}{|c|c|c|c|c|c|}
\hline Case no. & $\begin{array}{c}\text { Total } \\
\text { resistance } \\
{[\mathrm{N}]}\end{array}$ & $\begin{array}{c}\text { Pressure } \\
\text { resistance } \\
{[\mathrm{N}]}\end{array}$ & $\begin{array}{c}\text { Pressure } \\
\text { resistance / } \\
\text { Total } \\
\text { resistance } \\
{[\%]}\end{array}$ & $\begin{array}{c}\text { Shear } \\
\text { resistance } \\
{[\mathrm{N}]}\end{array}$ & $\begin{array}{c}\text { Shear } \\
\text { resistance / } \\
\text { Total } \\
\text { resistance } \\
{[\%]}\end{array}$ \\
\hline 1 & 56.514 & 14.125 & 25.00 & 42.389 & 75.00 \\
\hline 2 & 62.407 & 19.439 & 31.14 & 42.981 & 68.86 \\
\hline 3 & 96.119 & 51.228 & 53.29 & 44.891 & 46.71 \\
\hline 4 & 98.191 & 52.707 & 53.68 & 45.483 & 46.32 \\
\hline 5 & 74.191 & 29.730 & 40.08 & 44.461 & 59.92 \\
\hline
\end{tabular}

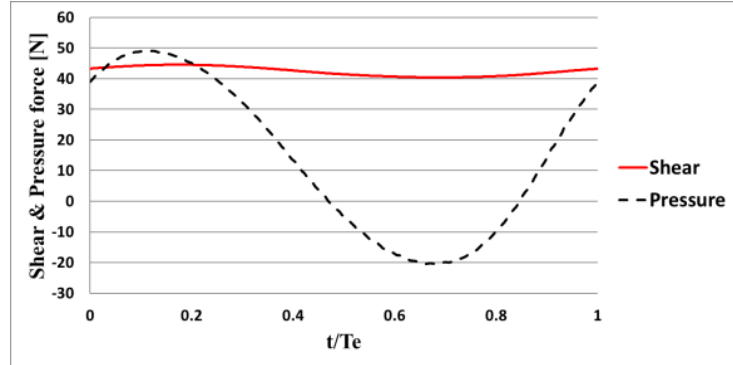

(a) Case $1\left(\lambda / L_{P P}=0.65\right)$

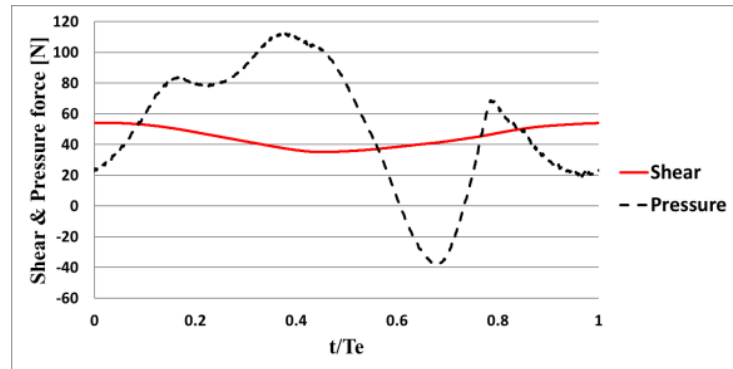

(c) Case $3\left(\lambda / L_{P P}=1.15\right)$

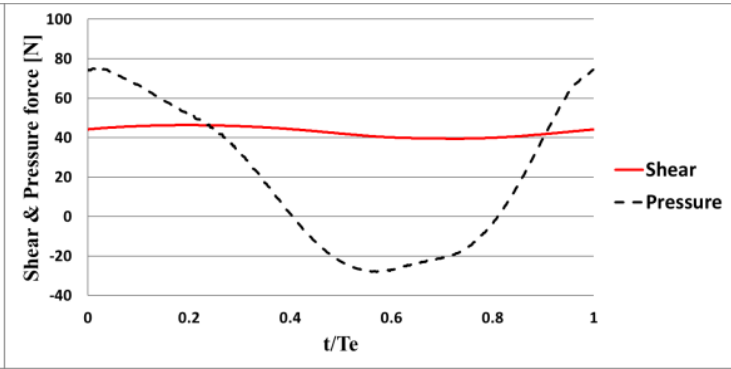

(b) Case $2\left(\lambda / L_{P P}=0.85\right)$

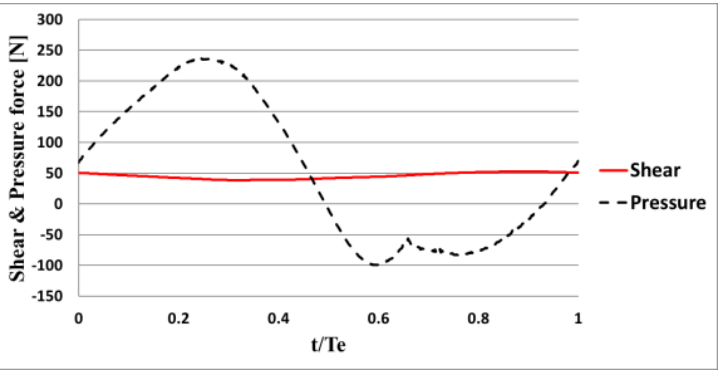

(d) Case $4\left(\lambda / L_{P P}=1.37\right)$ 
Numerical simulations of added resistance in regular head waves on a container ship
Young-Gill Lee, Cheolho Kim, Jeong-Ho Park Hyeongjun Kim, Insu Lee, Bongyong Jin

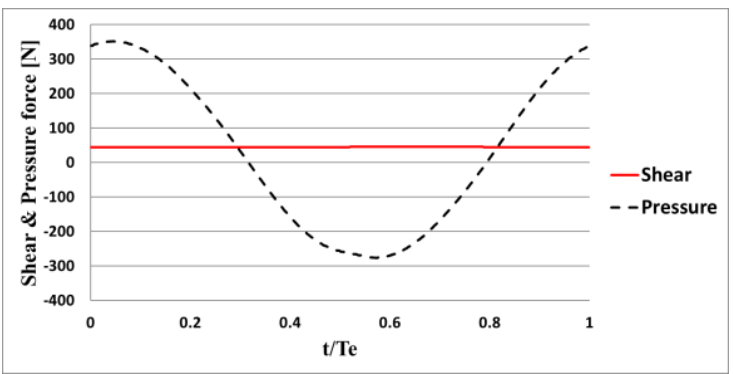

(e) Case $5\left(\lambda / L_{P P}=1.95\right)$

Fig. 20 Time history of pressure and shear force in waves over one encounter period

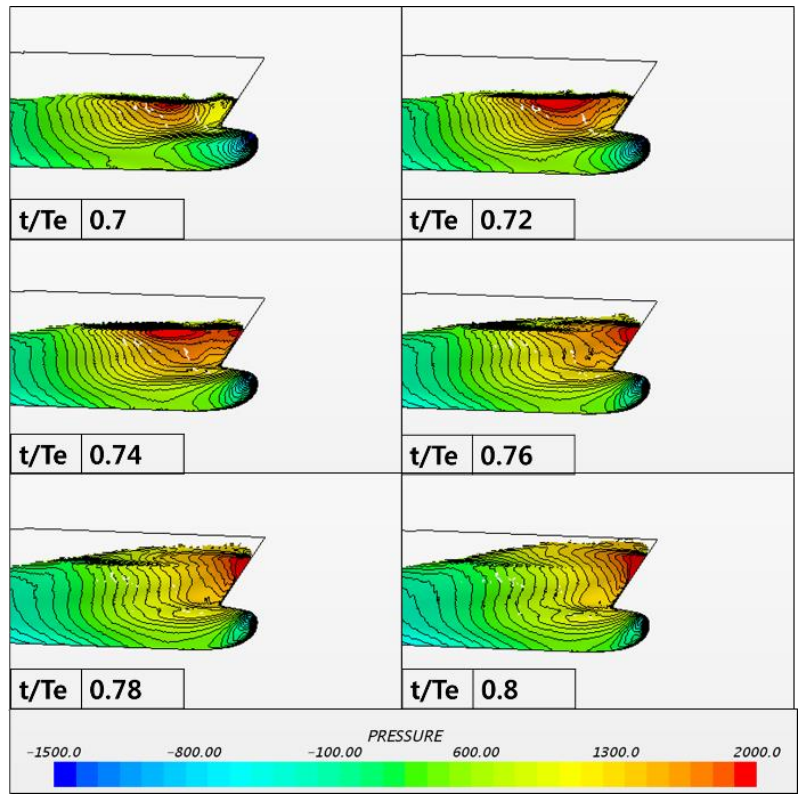

Fig. 21 Dynamic pressure contours on the hull surface in wave $\left(\lambda / L_{P P}=1.15\right)$ 


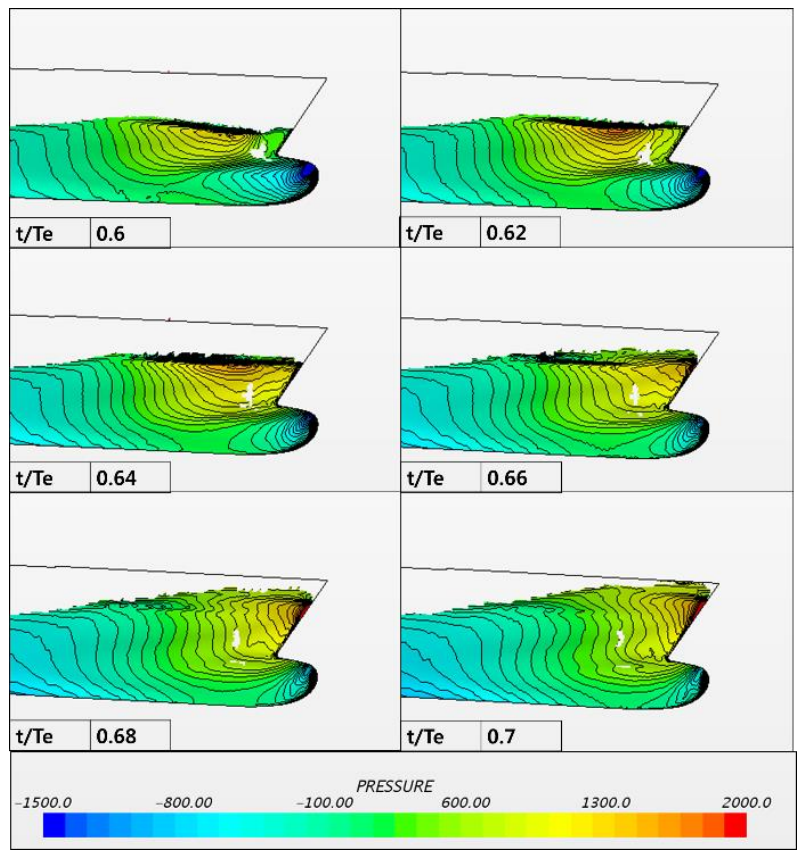

Fig. 22 Dynamic pressure contours on the hull surface in wave $\left(\lambda / L_{P P}=1.37\right)$

\section{Conclusions}

In this research, the numerical simulations of the added resistance and the motion response of the KCS hull form including the rudder in the regular head waves were conducted. The wave generation and damping zone were not set by using the wave forcing of the commercial CFD program STAR-CCM+. Also, the grid system did not need to refine and move by using DFBI.

The waves were compared with the Stokes' 5th-order wave theory. In this research, 10 to 20 grids were generated in the incoming waves along the vertical direction and the ratio of the horizontal and vertical $\Delta \mathrm{x} / \Delta \mathrm{z}$ was constrained at 8 .

When the added resistance and motion response results depended on the presence of the wave forcing, the results without the wave forcing confirmed that the result showed long period oscillation. When a wave was generated by applying wave forcing, the difference between the simulation and theory was less than $1 \%$ and the wave generation was confirmed reproducible. In the comparison of the added resistance and motion response simulation results, each wave period total resistance difference was less than 4\%. Also, the heave and pitch motion response showed similar results with those of the experiments. Differences were below 5\%. Furthermore, the added resistance difference between the simulation and experimental results was around $10 \%$. The average of pressure and shear force with regard to the total resistance were compared and the fact that the portion of shear force in total resistance is larger than that of pressure in the low period domain, confirmed the larger pressure portion around the natural period domain.

The reason for the non-linearity in the pressure distributions of case 3 and 4 was studied. The high pressure acting on the hull surface took place at the knuckle and the bow above the waterline, which confirms that the bow shape above the waterline has major effects on the added resistance.

The numerical method used in this research may be useful for calculating added resistance, motion response, etc. In this study, the numerical results of added resistance are compared with the experimental results and the difference is estimated to be within $10 \%$, and it is judged that estimation of added resistance occurred by waves in the seaway is possible 
through CFD. This will increase the accuracy of estimating the power of the engine and thus contribute to a more accurate calculation of the EEOI factor. In further study, numerical simulations of the added resistance and motion response of a KCS hull form with a rudder at other incidence angles of waves will be con-ducted and the results will be verified by comparing with the public experimental results of the 2015 Tokyo workshop (Case 2.11).

\section{ACKNOWLEDGMENT}

This work was supported by INHA UNIVERSITY Research Grant.

\section{REFERENCES}

[1] Lee, HY. \& Kwak, YK., 1997. "Analysis of Added Resistance of a Ship Advancing in Waves.” Journal of Korean Society of Ocean Engineering, 11(2), pp.91-99.

[2] Faltinsen, O.M., 2005. Hydrodynamics of High-Speed Marine Vehicles. Cambridge: New York.

[3] Nabergoj R. \& Prpic-Orsic J., 2007. "A comparison of different methods for added resistance prediction." 22nd IWWWFB, Zagreb, Croatia, 15 April 2007, pp.149-152.

[4] Storm-Tejsen, J. Yeh, H.Y.H \& Moran, D.D., 1973. "Added Resistance in Waves.” Society of Naval Architects and Marine Engineers Transactions, 81, pp. 250-279.

[5] Gerritsma, J. \& Beukelman, W., "1972. Analysis of the Resistance Increase in Waves of a Fast Cargo Ship.” International Shipbuilding Progress, 19(217), pp.285-293. https://doi.org/10.3233/ISP-19721921701

[6] Fujii, H. \& Takahashi, T., 1975. "Experimental study on the resistance increase of a ship in regular oblique waves." Proceeding of the 14th ITTC, Ottawa, September 1975, pp. 351-360. https://doi.org/10.2534/jjasnaoe1968.1975.132

[7] Nakamura, S. \& Naito, S., 1977. "Propulsive Performance of a Containership in Waves.” Journal of the Society of Naval Architects of Japan, 15, pp. 24-48.

[8] Journee, J.M.J., 1992. "Experiments and calculations on 4 wigley hull forms in head waves.” Delft university of technology report No 0909. Delft: Delft University.

[9] Kuroda, M. Tsujimoto, M. Sasaki, N. Ohmatsu, S. \& Takagi, K., 2011. "Study on the Bow Shapes Above the Waterline in View of the Powering and Greenhouse Gas Emission in Actual Seas." Journal of Engineering for the Maritime Environment, 226(1), pp.23-35.

[10] Park, DM. Lee, J. \& Kim, Y., 2015. "Uncertainty analysis for added resistance experiment of KVLCC2 ship.” Ocean Engineering, 95, pp.143-156. https://doi.org/10.1016/j.oceaneng.2014.12.007

[11] Seo, S. \& Park, SS., 2017. "Numerical Simulations of Added Resistance and Motions of KCS in Regular Head Waves." Journal of the Society of Naval Architects of Korea, 54(2), pp.132-142. https://doi.org/10.3744/SNAK.2017.54.2.132

[12] Maruo, H., 1960. "The drift of a body floating on waves.” Journal of Ship Research, 4, pp.1-10.

[13] Faltinsen, O.M. Minsaas, K.J. Liapis, N. \& Skjørdal, S.O., 1980. "Prediction of resistance and propulsion of a ship in a seaway." Proceeding of 13th Symposium on Naval Hydrodynamics, Tokyo, Japan, 6-10 October 1980, pp.505-529.

[14] Oh, S. Yang, J. \& Park, SH., 2015. “Computational and Experimental Studies on Added Resistance of AFRAMAX-Class Tankers in Head Seas.” Journal of the Society of Naval Architects of Korea, 52(6), pp.471-477. https://doi.org/10.3744/SNAK.2015.52.6.471

[15] Seo, MG. Kim, KH. Park, DM. \& Kim, Y., 2013. "Comparative Study on Added Resistance for Different Hull Forms by using Weakly-Nonlinear Seakeeping Formulations.” Journal of the Society of Naval Architects of Korea, 50(1), pp.49-58. https://doi.org/10.3744/SNAK.2013.50.1.49

[16] Oh, S. \& Yang, J., 2016. “A Study on Estimation of Added Resistance in Waves Using Modified Radiated Energy Method and Short Wave Correction Method." Journal of the Society of Naval Architects of Korea, 53(1), pp.62-68. https://doi.org/10.3744/SNAK.2016.53.1.62 
Young-Gill Lee, Cheolho Kim, Jeong-Ho Park , Hyeongjun Kim, Insu Lee, Bongyong Jin
Numerical simulations of added resistance in regular head waves on a container ship

[17] Jeong, YW. Kim, Y. \& Park, DM., 2017. "Study on Ship Performance in a Seaway for Application to Early Stage of Hull-Form Design.” Journal of the Society of Naval Architects of Korea, 54(3), pp.171186. https://doi.org/10.3744/SNAK.2017.54.3.171

[18] Jeong, KL. \& Lee, YG., 2014. "Numerical Simulation of the Flow around Advancing Ships in Regular Waves using a Fixed Rectilinear Grid System.” Journal of Korean Society of Ocean Engineering, 51(5), pp.419-428

[19] Orihara, H. \& Miyata, H., 2003. "Evaluation of Added Resistance in Regular Incident Waves by Computational Fluid Dynamics Motion Simulation using an Overlapping Grid System.” Journal of Marine Science and Technology, 8(2), pp.47-60. https://doi.org/10.1007/s00773-003-0163-5

[20] Hu, C. \& Kashiwagi, M., 2007. "Numerical and experimental studies on three-dimensional water on deck with a modified Wigley model." 9th International Conference on Numerical Ship Hydrodynamics, Ann Arbor, Michigan, 5-8 August 2007.

[21] Visonneau, M. et al., 2010. "Ship motions in moderate and steep waves with an interface capturing method." 9th International Conference on Hydrodynamics, Shanghai, China, 11-15 October 2010.

[22] Park, IR. Kim, J. Kim, YC. Kim, KS. Van, SH. \& Suh, SB., 2013. "Numerical Prediction of Ship Motions in Wave using RANS Method.” Journal of the Society of Naval Architects of Korea, 50(4), pp.232-239. https://doi.org/10.3744/SNAK.2013.50.4.232

[23] Yang, KK. Lee, JH. Nam, BW. \& Kim, Y., 2013. “Analysis of Added Resistance using a Cartesian-Gridbased Computational Method.” Journal of the Society of Naval Architects of Korea, 50(2), pp.79-87. https://doi.org/10.3744/SNAK.2013.50.2.79

[24] Tezdogan T, Demirel YK, Kellett P et al., 2015. "Full-scale unsteady RANS CFD simulations of ship behaviour and performance in head seas due to slow steaming." Journal of Ocean Engineering, (97), pp. 186-206.

[25] Kim, YJ. \& Lee, SB., 2017. "Effects of Trim Conditions on Ship Resistance of KCS in Short Waves." Journal of the Society of Naval Architects of Korea, 54(3), pp.258-266. https://doi.org/10.3744/SNAK.2017.54.3.258

[26] National Maritime Research Institute, 2015. Tokyo 2015 A workshop on CFD in ship hydro-dynamics. [Online] (Updated 1 August 2016) Available at: http://www.t2015.nmri.go.jp [Accessed 18 October 2016].

[27] Patankar, S.V. \& Spalding, D.B., 1972. "A calculation procedure for heat, mass and momentum transfer in three-dimensional parabolic flows.” International Journal of Heat and Mass Transfer, 15, pp.17871806. https://doi.org/10.1016/0017-9310(72)90054-3

[28] Weiss, J.M. Maruszewski, J.P. \& Smith, W.A., 1999. "Implicit solution of preconditioned navier-stokes equations using algebraic multigrid.” AIAA Journal, 37(1), pp.29-36. https://doi.org/10.2514/2.689

[29] Choi, J. \& Yoon, SB., 2009. "Numerical simulations using momentum source wave-maker applied to RANS equation model”, Coastal Engineering, 56(10), pp.1043-1060. https://doi.org/10.1016/j.coastaleng.2009.06.009

[30] Kim, J. W., O’Sullivan, J., \& Read, A., 2012. "Ringing Analysis on a Vertical Cylinder by Euler Overlay Method", OMAE2012-84091.

[31] STAR-CCM+ Documentation Version 11.06, 2016. 2016 Siemens PLM Software.

Submitted: $\quad$ 18.05.2018. $\quad$ Young-Gill Lee, younglee@inha.ac.kr

Dept. of Naval Architecture and Ocean Engineering, Inha University,

Incheon, Republic of Korea

Corresponding author: Cheolho Kim, cheolho.kim@siemens.com

Siemens Industry Software Ltd., Republic of Korea

Jeong-Ho Park, john523933@gmail.com

Dept. of Naval Architecture and Ocean Engineering, Graduate School, Inha

University, Incheon, Republic of Korea

Hyeongjun Kim, hjkim@hhi.co.kr

Ship Navigation Research Department, Hyundai Maritime Research Institute,

Hyundai Heavy Industries., Republic of Korea

Insu Lee, insu.lee@siemens.com

Siemens Industry Software Ltd., Republic of Korea

Bongyong Jin, bongyong.jin@ siemens.com

Siemens Industry Software Ltd., Republic of Korea 